\title{
Detailed comparisons of airborne formaldehyde measurements with box models during the 2006 INTEX-B and MILAGRO campaigns: potential evidence for significant impacts of unmeasured and multi-generation volatile organic carbon compounds
}

\author{
A. Fried ${ }^{1}$, C. Cantrell ${ }^{2}$, J. Olson ${ }^{3}$, J. H. Crawford ${ }^{3}$, P. Weibring ${ }^{1}$, J. Walega ${ }^{1}$, D. Richter ${ }^{1}$, W. Junkermann ${ }^{4}$, \\ R. Volkamer ${ }^{5}$, R. Sinreich ${ }^{5}$, B. G. Heikes ${ }^{6}$, D. O'Sullivan ${ }^{7}$, D. R. Blake ${ }^{8}$, N. Blake ${ }^{8}$, S. Meinardi ${ }^{8}$, E. Apel ${ }^{2}$, \\ A. Weinheimer ${ }^{2}$, D. Knapp ${ }^{2}$, A. Perring ${ }^{9}$, R. C. Cohen $^{9}$, H. Fuelberg ${ }^{10}$, R. E. Shetter ${ }^{2}$, S. R. Hall ${ }^{2}$, K. Ullmann ${ }^{2}$, \\ W. H. Brune ${ }^{11}$, J. Mao ${ }^{12}$, X. Ren ${ }^{13}$, L. G. Huey ${ }^{14}$, H. B. Singh ${ }^{15}$, J. W. Hair ${ }^{16}$, D. Riemer ${ }^{13}$, G. Diskin ${ }^{17}$, and \\ G. Sachse ${ }^{17}$ \\ ${ }^{1}$ The National Center for Atmospheric Research, Earth Observing Laboratory, 3450 Mitchell Lane, Boulder, CO, USA \\ ${ }^{2}$ The National Center for Atmospheric Research, Atmospheric Chemistry Division, 3450 Mitchell Lane, Boulder, CO, USA \\ ${ }^{3}$ NASA Langley Research Center, Hampton, VA, USA \\ ${ }^{4}$ Karlsruhe Institute of Technology, IMK-IFU, Garmisch-Partenkirchen, Germany \\ ${ }^{5}$ The University of Colorado, Dept. of Chemistry, Boulder, CO, USA \\ ${ }^{6}$ The University of Rhode Island, Narragansett, RI, USA \\ ${ }^{7}$ United States Naval Academy, Annapolis, MD, USA \\ ${ }^{8}$ University of California, Irvine, Irvine, CA, USA \\ ${ }^{9}$ University of California, Berkeley, Berkley, CA, USA \\ ${ }^{10}$ Florida State University, Tallahassee, Florida, USA \\ ${ }^{11}$ Pennsylvania State University, University Park, PA, USA \\ ${ }^{12}$ Harvard University, Cambridge, MA, USA \\ ${ }^{13}$ University of Miami, Miami, Fl, USA \\ ${ }^{14}$ Georgia Institute of Technology, Atlanta, GA, USA \\ ${ }^{15}$ NASA Ames Research, Moffett Field CA, USA \\ ${ }^{16}$ NASA Lidar Applications Group, Langley Research Center, Hampton, VA, USA \\ ${ }^{17}$ NASA Langley Research Center, Hampton, VA, USA
}

Received: 8 March 2011 - Published in Atmos. Chem. Phys. Discuss.: 24 March 2011

Revised: 31 October 2011 - Accepted: 12 November 2011 - Published: 30 November 2011

\begin{abstract}
Detailed comparisons of airborne $\mathrm{CH}_{2} \mathrm{O}$ measurements acquired by tunable diode laser absorption spectroscopy with steady state box model calculations were carried out using data from the 2006 INTEX-B and MILARGO campaign in order to improve our understanding of hydrocarbon oxidation processing. This study includes comparisons over Mexico (including Mexico City), the Gulf of Mexico, parts of the continental United States near the Gulf coast, as well as the more remote Pacific Ocean, and focuses on comparisons in the boundary layer. Select previous comparisons in other campaigns have highlighted some loca-
\end{abstract}

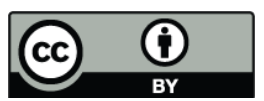

Correspondence to: A. Fried

(fried@ucar.edu) tions in the boundary layer where steady state box models have tended to underpredict $\mathrm{CH}_{2} \mathrm{O}$, suggesting that standard steady state modeling assumptions might be unsuitable under these conditions, and pointing to a possible role for unmeasured hydrocarbons and/or additional primary emission sources of $\mathrm{CH}_{2} \mathrm{O}$. Employing an improved instrument, more detailed measurement-model comparisons with better temporal overlap, up-to-date measurement and model precision estimates, up-to-date rate constants, and additional modeling tools based on both Lagrangian and Master Chemical Mechanism (MCM) runs, we have explained much of the disagreement between observed and predicted $\mathrm{CH}_{2} \mathrm{O}$ as resulting from non-steady-state atmospheric conditions in the vicinity of large pollution sources, and have quantified 
the disagreement as a function of plume lifetime (processing time). We show that in the near field (within $\sim 4$ to $6 \mathrm{~h}$ of the source), steady-state models can either over-orunderestimate observations, depending on the predominant non-steady-state influence. In addition, we show that even far field processes $(10-40 \mathrm{~h})$ can be influenced by non-steadystate conditions which can be responsible for $\mathrm{CH}_{2} \mathrm{O}$ model underestimations by $\sim 20 \%$. At the longer processing times in the 10 to $40 \mathrm{~h}$ range during Mexico City outflow events, MCM model calculations, using assumptions about initial amounts of high-order NMHCs, further indicate the potential importance of $\mathrm{CH}_{2} \mathrm{O}$ produced from unmeasured and multigeneration hydrocarbon oxidation compounds, particularly methylglyoxal, 3-hydroxypropanal, and butan-3-one-al.

\section{Introduction}

Formaldehyde $\left(\mathrm{CH}_{2} \mathrm{O}\right)$ is an important and ubiquitous trace gas found throughout the atmosphere. This gas, which is the most abundant aldehyde compound found in the atmosphere, is formed from the oxidation of most anthropogenic and biogenic hydrocarbons, primarily initiated by reactions with the hydroxyl $(\mathrm{OH})$ radical and ozone $\left(\mathrm{O}_{3}\right)$. Formaldehyde is also directly emitted into the atmosphere from biomass burning (Lee et al., 1997); incomplete combustion from motor vehicles (Herndon et al., 2005), potentially from petrochemical flares (Olaguer et al., 2009) and other sources; industrial emissions, and by emissions from vegetation (Carlier et al., 1986, and references therein). Typical atmospheric mixing ratios vary from approximately 1 part-per-billion by volume ( 1 ppbv, 1 part in $10^{9}$ parts of air) in the background continental boundary layer (Harder et al., 1997) to several 10's of ppbv for polluted air over urban regions (Dasgupta et al., 2005) and air influenced by petrochemical refinery emissions (primarily ethene and propene) during summer months (Wert et al., 2003). In the remote background atmosphere by contrast, the oxidation of methane $\left(\mathrm{CH}_{4}\right)$ becomes the dominant source of $\mathrm{CH}_{2} \mathrm{O}$. In these cases, ambient $\mathrm{CH}_{2} \mathrm{O}$ mixing ratios are typically on the order of several hundred parts-per-trillion by volume ( $1 \mathrm{pptv}, 1$ part in $10^{12}$ parts of air) near the surface, and on the order of $50 \mathrm{pptv}$ or less in the upper troposphere above $8 \mathrm{~km}$ unperturbed by convection (Fried et al., 2003b; Stickler et al., 2006). Formaldehyde is also produced from numerous other precursor compounds, including methyl hydroperoxide $\left(\mathrm{CH}_{3} \mathrm{OOH}, \mathrm{MHP}\right)$, methanol $\left(\mathrm{CH}_{3} \mathrm{OH}\right)$, and isoprene, to name a few.

Formaldehyde primarily decomposes via three pathways, two involving photolysis and one with $\mathrm{OH}$. At wavelengths less than 339-nm the quantum yield for the radical photolysis channel $\left(2 \mathrm{HO}_{2}+\mathrm{CO}\right)$ is non-zero, and this channel becomes dominant at wavelengths less than about 324-nm, while at longer wavelengths than this but shorter than 361$\mathrm{nm}$ the molecular decomposition channel $\left(\mathrm{H}_{2}+\mathrm{CO}\right)$ is domi- nant (Sander et al., 2006). Under certain circumstances (high altitudes, large solar zenith angels and/or dry conditions), the radical photolysis channel of $\mathrm{CH}_{2} \mathrm{O}$ can dominate over other $\mathrm{HO}_{\mathrm{x}}$ production pathways. In the presence of sufficient $\mathrm{NO}$, the $\mathrm{HO}_{2}$ radicals from this channel result in the production of ozone. In Mexico City, $\mathrm{CH}_{2} \mathrm{O}$ photolysis is responsible for about $20-25 \%$ of $\mathrm{HO}_{\mathrm{x}}$ radicals on a 12 -h average daytime basis (Dusanter et al., 2009; Volkamer et al., 2010), and hence adds substantially to the efficient formation of ozone and secondary organic aerosols (SOA) (Lei et al., 2008). Lei et al. (2009) further report that primary emissions of $\mathrm{CH}_{2} \mathrm{O}$ in the Mexico City Metropolitan Area enhances daytime radical production and peak ozone concentrations by up to $10 \%$ and $8 \%$, respectively.

Because of the relatively short lifetime of $\mathrm{CH}_{2} \mathrm{O}$ (several $\mathrm{h}$ at mid-day), it is a good tracer for recent photochemical activity of hydrocarbons. Since $\mathrm{CH}_{2} \mathrm{O}$ is produced as an intermediate from the oxidation of many hydrocarbons, it also serves as an important test species in evaluating our mechanistic understanding of tropospheric oxidation reactions, which is often done through comparisons of time coincident $\mathrm{CH}_{2} \mathrm{O}$ observations with box models. Numerous studies have been devoted to this topic, and recent examples include Fried et al. (2003a, b), Fried et al. (2008a, b), Kormann et al. (2003) and references therein, and Junkermann et al. (2009). As discussed in these references, box models have at times: underestimated, overestimated, or accurately simulated $\mathrm{CH}_{2} \mathrm{O}$ observations, depending upon the measurement regime.

In the lower troposphere typically below $2 \mathrm{~km}$, box models have often underestimated $\mathrm{CH}_{2} \mathrm{O}$ observations. This problem is particularly acute in the presence of fresh emissions (Fried et al., 2003b, 2008a), either fresh emissions of $\mathrm{CH}_{2} \mathrm{O}$ and/or its very reactive precursors such as ethene and isoprene. The modeling studies listed above have used a steady-state modeling approach that is constrained by in-situ measurements of precursor species concentrations. This approach does not include direct $\mathrm{CH}_{2} \mathrm{O}$ emission sources and is limited to instantaneous measurements of non-methane hydrocarbons and other precursors. In the vicinity of large and relatively fresh emissions, this approach may underestimate the recent history of photochemical production of $\mathrm{CH}_{2} \mathrm{O}$ from very short-lived hydrocarbons during rapid decay just prior to the point of measurement. In the case of isoprene, furthermore, $\mathrm{CH}_{2} \mathrm{O}$ will continue to be produced from higher generation isoprene oxidation products even when the parent isoprene molecule has decayed away, resulting in model underestimations many $\mathrm{h}$ after emission. The steady state modeling approach is also dependent upon the availability of measurements of important $\mathrm{CH}_{2} \mathrm{O}$ precursors such as MHP and methanol. In the case of fresh pollution, unmeasured hydrocarbon species may present another model limitation. In addition, it becomes more important to assure precise data overlap within fresh plumes. Timescales for data averaging that are typically used for modeling purposes (e.g., 1-min) 
may not be sufficient to capture ambient high-resolution data variability. In fact, the four largest $\mathrm{CH}_{2} \mathrm{O}$ measurement/model ratios observed during the INTEX-NA study (Fried et al., 2008a) all resulted from poor temporal overlap between $\mathrm{CH}_{2} \mathrm{O}$ and its precursors. Fried et al. (2003b) have also shown that when physical sink processes are missing from models, such as the uptake of $\mathrm{CH}_{2} \mathrm{O}$ and $\mathrm{MHP}$ within clouds and in the lower marine troposphere, box models can overestimate observations. However, in the absence of these effects, Fried et al. (2003b, 2008a) have also shown that despite point-to-point scatter, on average one can obtain good overall agreement between $\mathrm{CH}_{2} \mathrm{O}$ measurements and box model calculations away from local sources in the mid to upper troposphere. This implies that several $\mathrm{CH}_{2} \mathrm{O}$ lifetimes away from such sources and sinks we generally have a good understanding of $\mathrm{CH}_{2} \mathrm{O}$ chemistry in the background mid to upper troposphere.

However, the various studies by our group, employing observations based on tunable diode laser absorption spectroscopy, and by other groups continue to point to persistent unresolved model underestimates of $\mathrm{CH}_{2} \mathrm{O}$ in the boundary layer (operationally defined here as radar altitudes between the surface and $2 \mathrm{~km}$ ), and this includes air masses far from local emission sources. During INTEX-NA (Fried et al., 2008a), for example, model underestimations by approximately a factor of two were observed in the boundary layer over the Atlantic Ocean over $1000 \mathrm{~km}$ from the nearest land source. Such discrepancies during the TRACE-P (Fried et al., 2003b) and INTEX-NA (Fried et al., 2008a) studies progressively increased with increasing ambient $\mathrm{CH}_{2} \mathrm{O}$ levels. Over the Gulf of Mexico and the remote tropical Pacific Ocean, unexplained and high concentrations of $\mathrm{CH}_{2} \mathrm{O}$ and other oxygenated VOCs have been observed in the boundary layer up to $3000 \mathrm{~km}$ from land (Sinreich et al., 2010; Coburn et al., 2011). Over the continental United States during the INTEX-NA study, median box model results underestimated median $\mathrm{CH}_{2} \mathrm{O}$ observations by as much as $\sim 700 \mathrm{pptv}$ in the boundary layer (Fried et al., 2008a). In addition to the possibility of measurement and/or model imprecision, systematic measurement errors from spectroscopic interferences and errors caused by poor temporal overlap between $\mathrm{CH}_{2} \mathrm{O}$ observations and model inputs, which are primarily dependent upon the hydrocarbon (HC) precursors, the boundary layer discrepancies could also arise from: unmeasured hydrocarbons; non-steady state environmental conditions, which may occur near large pollution sources; direct $\mathrm{CH}_{2} \mathrm{O}$ emissions and transport of such direct emissions; processes which are not included in the box model such as production from heterogeneous/multiphase oxidation or losses to aqueous phases; errors in reaction rate constants and/or photolysis rates; and $\mathrm{CH}_{2} \mathrm{O}$ production from the breakdown of reactive intermediates that are formed via multi-generation oxidation processes, analogous to the formation of SOA; or some combination of these.
The present airborne (INTEX-B/MILAGRO) study over Mexico (including the Mexico City Metropolitan area), the Gulf of Mexico, parts of the continental United States near the Gulf coast, as well as the more remote Pacific Ocean, provides an opportunity to further examine $\mathrm{CH}_{2} \mathrm{O}$ measurementbox model relationships over a wide geographic range spanning measurements near the surface to $12 \mathrm{~km}$ and over widely differing $\mathrm{CH}_{2} \mathrm{O}$ regimes. In addition, this study carefully examines $\mathrm{CH}_{2} \mathrm{O}$ measurement and model precision estimates to establish conservative combined $2 \sigma$ imprecision bounds for various sampling regimes. These bounds are then used to identify sampling regimes where systematic measurementbox model differences are important.

\section{Overview of present study}

Data for the present study were acquired onboard the NASA DC-8 aircraft during the Intercontinental Transport Experiment-Phase B (INTEX-B) study, as part of the 2006 MILAGRO campaign, which took place in the spring (4 March-15 May) of 2006 (Singh et al., 2009; Molina et al., 2010). This paper primarily focuses on comparisons in the boundary layer, with an emphasis on comparisons very close to large emission sources and comparisons during air mass aging in Mexico City outflow events. In particular, the present study examines $\mathrm{CH}_{2} \mathrm{O}$ measurement-model discrepancies as a function of photochemical processing times. Formaldehyde comparisons above the boundary layer and over more remote regions of the Pacific Ocean are also discussed to provide contrasting behavior.

There were two independent $\mathrm{CH}_{2} \mathrm{O}$ instruments operating on the DC-8: a tunable diode laser absorption spectrometer (TDLAS) developed and operated by our group at NCAR (see Appendix A) and an enzyme fluorescence detection (EFD) system developed and operated by the University of Rhode Island. A discussion of past comparisons between these two instruments can be found in Fried et al. (2008a) and references therein. Although comparisons between these two instruments are indeed important, this is the topic of other papers (Kleb et al., 2011 as one example). The present study exclusively focuses on $\mathrm{CH}_{2} \mathrm{O}$ measurements acquired by the TDLAS system. The long history of such measurements with box model comparisons using the same measurement methodology spanning nine years allows us to assess measurement-model relationships in a more straightforward way as functions of geographic region and time. In addition, for reasons that will become clear, fast 1-s airborne $\mathrm{CH}_{2} \mathrm{O}$ measurements possible with the TDLAS system are an important aspect of the present study where temporal overlap between measurements and box model inputs are considered.

The INTEX-B study was carried out in two phases: the first phase (4 March-22 March), which is shown by blue flight tracks in Fig. 1, focuses on Mexico, the Gulf of Mexico, and the Gulf coast of the United States. The second 


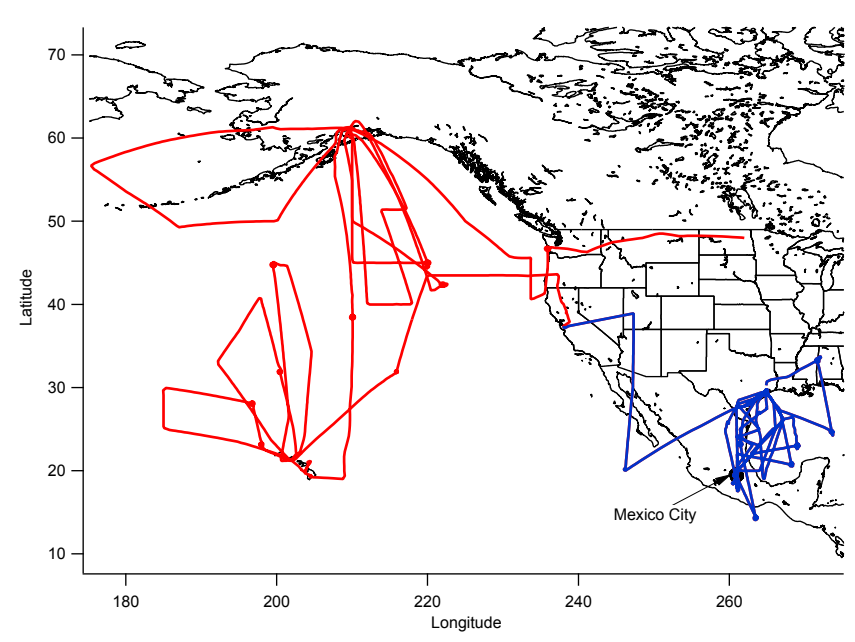

Fig. 1. DC-8 flight tracks during the INTEX-B first mission phase (blue) and second mission phase (red) on the hydrocarbon time base.

phase (17 April-15 May), which is depicted by the red flight tracks, focuses on the remote Pacific Ocean and coastal regions of Alaska. Although this study employs the same $\mathrm{CH}_{2} \mathrm{O}$ TDLAS measurement approach and the same box modeling approach as the TRACE-P and INTEX-NA studies, a number of improvements have been incorporated into the present comparisons, and this can provide additional information about the sources of these boundary layer discrepancies. First, a number of enhancements to the TDLAS system were implemented, which resulted in improvements to measured $\mathrm{CH}_{2} \mathrm{O}$ detection limits by an average factor of 1.6 relative to the INTEX-NA study. It is important to note that these improvements only affect measurement precision and not overall measured $\mathrm{CH}_{2} \mathrm{O}$ mixing ratios. Secondly, to eliminate the issue of poor temporal overlap between $\mathrm{CH}_{2} \mathrm{O}$ measurements and the model inputs, which are primarily limited by the data collection rate of hydrocarbon $(\mathrm{HC})$ precursors, we consider here comparisons on the $\mathrm{HC}$ time base rather than comparisons based solely on the official 1-min merged data (http://www-air.larc.nasa.gov/missions/intex-b/ intexb.html). To accomplish this, 1-s $\mathrm{CH}_{2} \mathrm{O}$ TDLAS measurements were integrated over the start and stop times of the $\mathrm{HC}$ database, which is typically on the order of $1 \mathrm{~min}$ or more. We also derive a more restricted dataset where $\mathrm{CH}_{2} \mathrm{O}$ measurements comprised at least $50 \%$ of the $\mathrm{HC}$ time base and where the measurements were uniformly distributed over this time base. This restricted dataset was further limited to time periods where there were MHP measurements to constrain the box model (see Fried et al., 2003b and 2008a and references therein for the importance of this factor).

To address the potential issue of systematic measurement errors due to unknown spectroscopic interferences, we show comparisons of boundary layer $\mathrm{CH}_{2} \mathrm{O}$ measurements acquired by the TDLAS system during DC- 8 overflights over
Mexico City ground-based supersites where there were independent $\mathrm{CH}_{2} \mathrm{O}$ measurements based upon in situ Hantzsch liquid phase fluorometric detection systems as well as MAXDOAS systems. Additional comparisons between airborne spectroscopic $\mathrm{CH}_{2} \mathrm{O}$ measurements and these two groundbased systems were also carried out using a newly developed difference frequency generation (DFG) instrument developed by our group operating on the NCAR C-130 aircraft. Even though this DFG system was based on a different laser source than the DC-8 TDLAS system, both instruments use the same $\mathrm{CH}_{2} \mathrm{O}$ absorption feature, have similar laser linewidths, and employ the same calibration, measurement, zeroing, and fitting approaches. Thus any systematic error in one instrument, in all likelihood, should also be reflected in the other. The airborne intercomparison of these two instruments (not blind in this case) on 19 March when the DC- 8 and C-130 were flying in close formation near Mexico City produced a linear regression (TDLAS versus DFG) slope of 1.018 and an intercept of 3 pptv (measurement range $\sim 500 \mathrm{pptv}$ to $3500 \mathrm{pptv}$ ). The $1 \mathrm{~s}$ TDLAS measurements were averaged over the 30-s DFG time base for this comparison. The comparisons of this study also include a careful reassessment of model uncertainties. In previous comparisons during INTEX-NA and TRACE-P (Fried et al., 2008a and 2003b), we adopted the model sensitivity analysis of Frost et al. (2002) to arrive at an approximate model random uncertainty of $24 \%(2 \sigma)$ times the model mixing ratio. The general approach of Frost et al. (2002) is used here to estimate the component of model uncertainty due to uncertainties in input constraints, utilizing environmental conditions and instrument uncertainties appropriate for the INTEX-B campaign. A Monte Carlo approach, using selected environmental and chemical conditions typical of geographical regions encountered during INTEX-B, is used to estimate the component of model uncertainty due to kinetic and photolytic rate uncertainties. More comprehensive discussions of the TDLAS measurement, steady state box model, and the measurement and modeling uncertainties can be found in Appendix A.

\section{Comparisons of Airborne $\mathrm{CH}_{2} \mathrm{O}$ measurements with ground-based measurements}

We have a long history of measurement comparisons between the present TDLAS system and earlier versions of this system with other $\mathrm{CH}_{2} \mathrm{O}$ measurement approaches, and Appendix B provides further discussions of this subject. During the present study there were a total of nine different time periods when either the DC- 8 or the C-130 passed close to ground sampling sites over Mexico City and where there was evidence of sampling in the same air mass as groundbased $\mathrm{CH}_{2} \mathrm{O}$ measurements acquired by either Hantzsch or DOAS systems. Appendix $\mathrm{C}$ and tables therein further discuss such comparisons, and the results are summarized in 


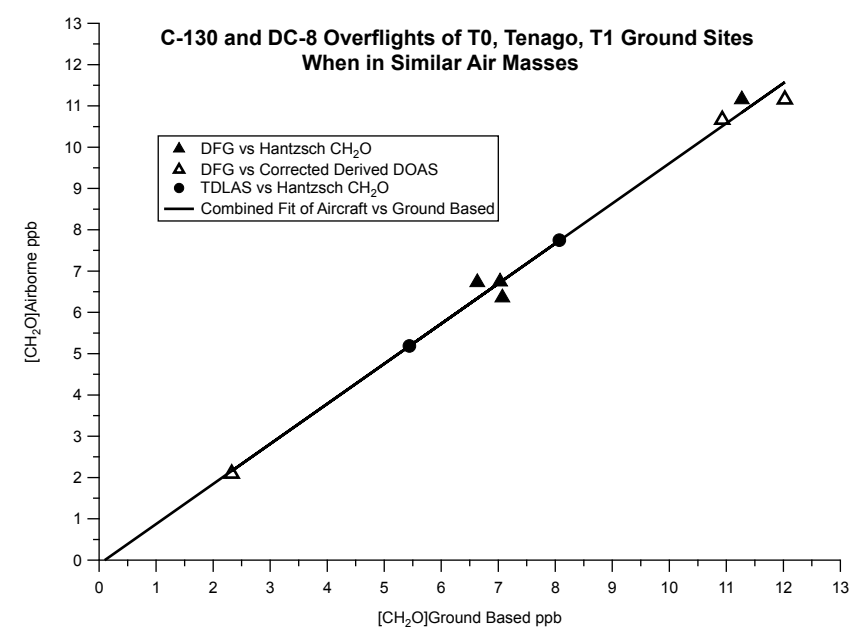

Fig. 2. Comparisons between aircraft measurements of $\mathrm{CH}_{2} \mathrm{O}$ from the C-130 and DC-8 during overflights with ground sites when coincident measurements were acquired by a Hantzsch system and/or a DOAS system. The DOAS $\mathrm{CH}_{2} \mathrm{O}$ mixing ratios were corrected by the ratio of the DOAS derived $\mathrm{NO}_{2}$ to $\mathrm{C}-130 \mathrm{NO}_{2}$ measurements as discussed in the text. The DC- $8 \mathrm{CH}_{2} \mathrm{O}$ measurements were acquired with the TDLAS system while the C-130 aircraft acquired DFG $\mathrm{CH}_{2} \mathrm{O}$ measurements. A linear regression of the 9 points yields a slope of $0.971 \pm 0.03$, an intercept of $-0.09 \pm 0.3 \mathrm{ppbv}$ and an $r^{2}$ of 0.992 .

Fig. 2. The airborne DC-8 and C-130 $\mathrm{CH}_{2} \mathrm{O}$ spectroscopic measurements are plotted on the y-axis as a function of the two ground-based measurements, and different comparisons are displayed using different symbols. As can be seen, the agreement among the measured/derived $\mathrm{CH}_{2} \mathrm{O}$ values is excellent: all $4 \mathrm{CH}_{2} \mathrm{O}$ mixing ratios fall on line with a slope of 0.97 and near zero intercept. This is consistent with the agreement obtained in past TDLAS-Hantzsch comparisons (Gilpin et al., 1997), past TDLAS-DOAS comparisons (Harder et al., 1997; Wert et al., 2003), and past HantzschDOAS comparisons (Hak et al., 2005), and provides additional confidence in the present airborne TDLAS measurements.

\section{Measurement-steady state box model comparisons}

Box model simulations were carried out employing the NASA Langley time dependent photochemical box model (Crawford et al., 1999; Olson et al., 2001, 2006). As discussed in Fried et al. (2008a), the model is constrained by the measurements of certain long-lived precursors, and calculates for each set of measurements the associated selfconsistent diurnal profile of radical and other computed species. Computed radical concentrations at the same point in time as the measurements are the instantaneous model results. This diurnal steady state (DSS) approach assures that all computed species are in equilibrium with the diurnal pro-

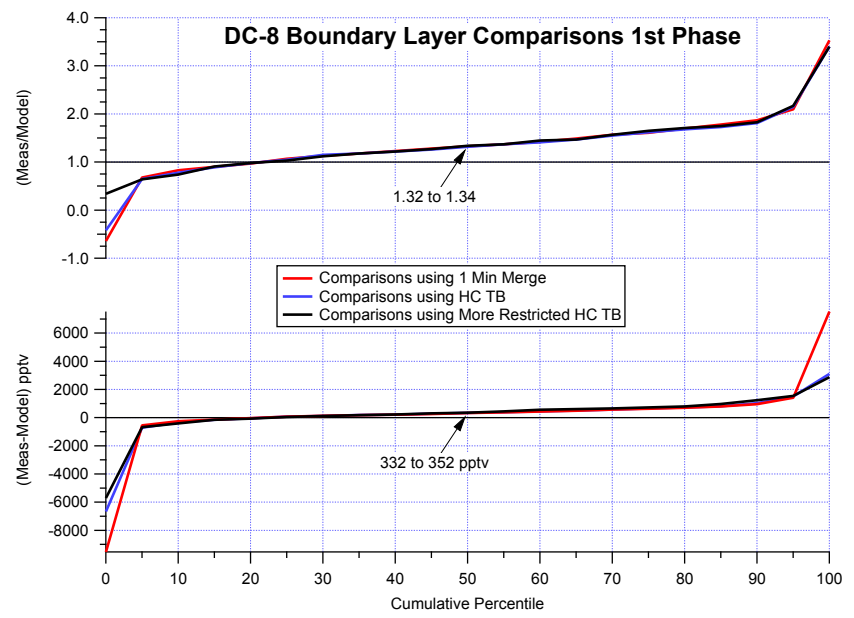

Fig. 3. Cumulative percentile measurement/model ratios (upper) and differences (lower) for DC-8 TDLAS-box model comparisons using the standard 1-min merged data set (red line), using the hydrocarbon time base merge (HC TB, blue line), and using the more restricted data on the HC TB (black line), as further discussed in the text. The median ratios and differences highlighted reflect the range of values for the 3 merges. Large measurement-model discrepancies in both the ratios and differences only occur in the lowest and highest $5 \%$ of the distributions, indicating that comparisons are not highly dependent on the type of merge.

cess. The uncertainty in box model predictions of $\mathrm{CH}_{2} \mathrm{O}$ and other radicals include a component due to uncertainties in the measurement of constrained species (model constraint uncertainty), and a component due to uncertainties in kinetic and photolytic rates (model kinetic uncertainty). More details regarding the box model and its uncertainties are given in Appendix A and references therein.

Figure 3 shows a plot of the cumulative percentage measurement/model ratios and (measurement-model) differences for the three different merge time bases discussed in the Introduction for the NASA DC-8 employing the TDLAS measurements. In the measurement-model comparisons of this study we show both the ratios and differences since each one has a drawback that can mask the true level of agreement: the ratio becomes unduly sensitive at low model values and the differences can be unduly large at high mixing ratios, which may in part reflect laser wavelength instabilities and/or the presence of spectral interferences. Figure 3 shows that large differences between the different merge time bases are only observed in the ratios and differences for the lowest and highest $5 \%$ of the distributions, indicating that the timescale for averaging is not that important, at least in the present study, for most of the comparisons. Unless indicated otherwise, this study employs DC-8 comparisons on the hydrocarbon time base; the more restricted data set reduces the number of boundary layer comparisons in the first phase from 347 down to 136 data points. Figure 3 shows that the median measurement-model ratios and differences 
Table 1. Radar altitude bin statistics for time coincident TDLAS measurements (Meas) and box model (Model) results on the hydrocarbon time base during the 1st phase of INTEX-B for the NASA DC-8. All measurement and model results, including (MeasModel) are in pptv. The difference and ratios were determined from the point-to-point comparisons (i.e. comparisons where the ratios and differences were first determined for each point and the altitudebinned medians of these were then calculated).

\begin{tabular}{lrrrrr}
\hline $\begin{array}{l}\text { Radar } \\
\text { Alt }(\mathrm{km})\end{array}$ & $\begin{array}{r}\text { Median } \\
\text { Meas }\end{array}$ & $\begin{array}{r}\text { Median } \\
\text { Model }\end{array}$ & $\begin{array}{r}\text { Median } \\
\text { (Meas-Model) }\end{array}$ & $\begin{array}{r}\text { Median } \\
\text { Meas/Model }\end{array}$ & $N$ \\
\hline 0 to 0.5 & 1635 & 1248 & 258 & 1.20 & 120 \\
0.5 to 1 & 1874 & 1297 & 424 & 1.28 & 65 \\
1 to 2 & 1285 & 909 & 403 & 1.47 & 92 \\
2 to 4 & 503 & 459 & 121 & 1.35 & 174 \\
4 to 6 & 107 & 111 & -26 & 0.85 & 86 \\
6 to 8 & 75 & 72 & -1 & 0.99 & 63 \\
8 to 10 & 44 & 57 & -11 & 0.77 & 50 \\
10 to 12 & 26 & 39 & -23 & 0.44 & 21 \\
\hline
\end{tabular}

in the boundary layer range between 1.32 to 1.34 and 332 to $352 \mathrm{pptv}$, respectively, for the $1 \mathrm{st}$ mission phase for the three different data sets. A similar figure for C-130 comparisons using only the 1-min merged data set (not shown), reveals similar but slightly higher discrepancies (median ratio of 1.47 and a median difference of $544 \mathrm{pptv}$ ). The median boundary layer measured values for the DC- 8 and C-130 are, respectively 1532 pptv and 2262 pptv, and the higher C-130 value no doubt plays a role in the higher $\mathrm{C}-130$ discrepancies.

Figure 4 plots radar altitude binned median DC- 8 measurement and box model time-coincident results for both phases of INTEX-B on the hydrocarbon time base along with the number of comparisons in each altitude bin. Eight radar altitude bins are used: $0-0.5 \mathrm{~km}, 0.5-1 \mathrm{~km}, 1-2 \mathrm{~km}, 2-4 \mathrm{~km}$, $4-6 \mathrm{~km}, 6-8 \mathrm{~km}, 8-10 \mathrm{~km}$, and $10-12 \mathrm{~km}$. Table 1 further tabulates the TDLAS-box model comparisons, which also includes differences and ratios determined from the pointto-point comparisons. As can be seen large model underestimates are observed for the three altitude bins below $2 \mathrm{~km}$ during the first mission phase, which focuses on Mexico, the Gulf of Mexico and the Gulf coast of the United States. The point-to-point comparisons of Table 1 also reveal model $\mathrm{CH}_{2} \mathrm{O}$ underestimation in the 2 to $4 \mathrm{~km}$ altitude range, which is not apparent in the plot of the median mixing ratios. By contrast during the second phase, which was primarily over remote regions of the Pacific Ocean, the median TDLAS measured and modeled $\mathrm{CH}_{2} \mathrm{O}$ mixing ratios as well as pointto-point differences are all in good agreement at all altitudes, as further shown in Table 2. This is in contrast to boundary layer comparisons over the open Atlantic Ocean during INTEX-NA. In the 0 to $0.5 \mathrm{~km}$ bin, Fried et al. (2008a) report a median measurement/model ratio of 1.56 compared to a ratio of 1.15 observed in this study over the generally cleaner Pacific Ocean. As mentioned previously, we believe

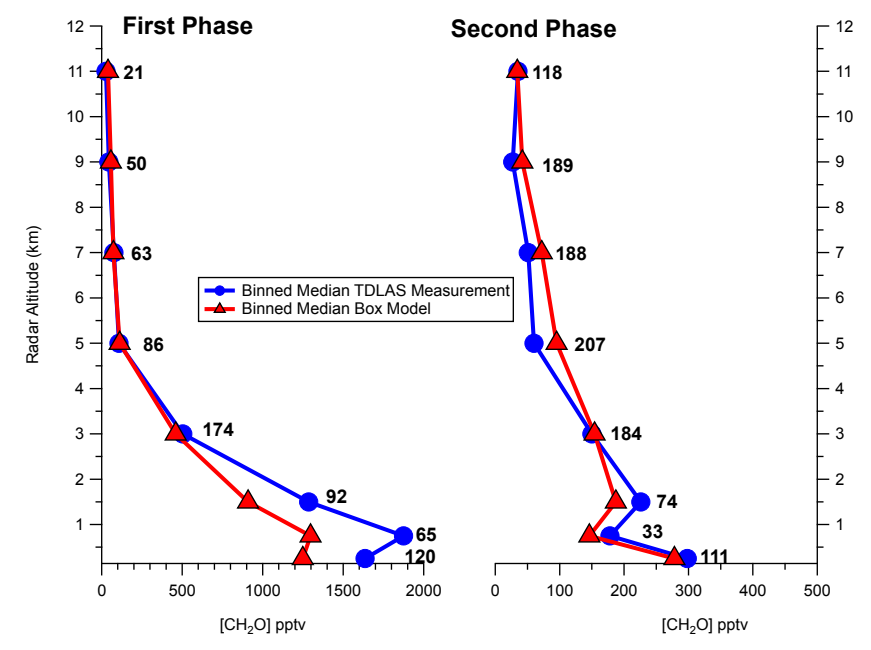

Fig. 4. Radar altitude binned medians for both mission phases. Data are averaged on hydrocarbon time base. The numbers denote the number of time coincident TDLAS measurements and model values in each bin.

Table 2. Radar altitude bin statistics for time coincident TDLAS measurements (Meas) and box model (Model) on hydrocarbon time base during the 2nd phase of INTEX-B for the NASA DC-8. All measurement and model results, including (Meas-Model) are in pptv. The difference and ratios were determined from the pointto-point comparisons.

\begin{tabular}{lrrrrr}
\hline $\begin{array}{l}\text { Radar } \\
\text { Alt }(\mathrm{km})\end{array}$ & $\begin{array}{r}\text { Median } \\
\text { Meas }\end{array}$ & $\begin{array}{r}\text { Median } \\
\text { Model }\end{array}$ & $\begin{array}{r}\text { Median } \\
\text { (Meas-Model) }\end{array}$ & $\begin{array}{r}\text { Median } \\
\text { Meas/Model }\end{array}$ & $N$ \\
\hline 0 to 0.5 & 298 & 278 & 39 & 1.15 & 111 \\
0.5 to 1 & 178 & 146 & 10 & 1.13 & 33 \\
1 to 2 & 226 & 187 & 1 & 1.01 & 74 \\
2 to 4 & 150 & 154 & -15 & 0.90 & 184 \\
4 to 6 & 60 & 95 & -35 & 0.58 & 207 \\
6 to 8 & 51 & 72 & -28 & 0.64 & 188 \\
8 to 10 & 27 & 42 & -27 & 0.46 & 189 \\
10 to 12 & 35 & 34 & -4 & 0.88 & 118 \\
\hline
\end{tabular}

this difference reflects the effects of North American outflow of $\mathrm{CH}_{2} \mathrm{O}$ precursors, which as will be shown later, can last several days downwind from the emission source. Although Pacific measurement-model ratios in this study are near 0.5 for the 3 altitude bins between 4 and $10 \mathrm{~km}$, the differences are small ranging between -35 and -27 pptv.

The comparisons of Fig. 4 raise the following question: are the observed TDLAS-box model boundary layer discrepancies during the first phase outside the combined measurement-model imprecision estimates? (see Appendix A for a discussion of imprecision and systematic measurement and model contributions). This is addressed in Figs. 5-8 where we plot altitude binned time coincident TDLAS measurement-model comparisons for four different geographic locations spanning both mission phases. We display 
the median TDLAS measurement and box model mixing ratios for each altitude bin (left side) along with the number of comparisons points, the median and individual point-topoint measurement/model ratios (center), the median and individual point-to-point (measurement-model) differences (right side). Also shown on the figures is the range of combined random measurement uncertainty and model constraint uncertainty expected for a given altitude bin at the $2 \sigma$ level. Figures 5-7 primarily reflect comparisons during the 1st phase while Fig. 8 exclusively reflects comparisons during the 2 nd phase. It is important to note that a given combined uncertainty in the difference represents an increasingly larger uncertainty in the ratio with altitude because of the decreasing absolute $\mathrm{CH}_{2} \mathrm{O}$ concentration values.

To account for the possibility that the TDLAS instrumental precision may be somewhat poorer in the boundary layer due to elevated $\mathrm{CH}_{2} \mathrm{O}$ levels, turbulence, and larger swings in cabin environmental conditions of temperature and pressure, which could potentially produce greater laser wavelength instabilities, we consider here the possibility that measurement imprecision limits in the boundary layer discussed in Appendix A may be higher than LOD estimates. To estimate the potential magnitude of this, we compare measurement precisions from the normalized 1-s data in the boundary layer with the in-flight-determined LODs based on all altitudes. For mixing ratios in the $1-2 \mathrm{ppbv}$ range, this produced boundary layer measurement precisions a factor of 1.4 to 2 times the in-flight-determined LOD values. Although this procedure also folds in more ambient variability than the LOD determinations (which overestimates the measurement imprecision), it provides the most conservative upper limit to the instrument precision in the boundary layer. These modified precision estimates were folded into the combined uncertainty estimates shown in Figs. 5-8. Likewise the model constraint uncertainty limits for the various altitude bins represent conservative upper limits here since we have not folded in the possibility that altitude bin-averaging of multiple data points may improve the overall model uncertainty, as suggested by independent Monte Carlo calculations. This also applies to the $\mathrm{CH}_{2} \mathrm{O}$ measurements. Nevertheless, the combined uncertainty bounds of Figs. 5-8 yield conservative upper limits beyond which random $\mathrm{CH}_{2} \mathrm{O}$ measurement and model constraint uncertainties cannot explain the discrepancies.

In Fig. 5, which depicts comparisons over the continental United States and Mexico (exclusive of Mexico City and Monterrey), one observes model underestimates in both the ratios and differences below $3 \mathrm{~km}$. The discrepancy peaks in the $0.5-1 \mathrm{~km}$ bin but is not evident in the $0-0.5 \mathrm{~km}$ bin. For altitude bins greater than $3 \mathrm{~km}$, the ratios and differences fall within the mutual uncertainty limits. As the combined imprecision estimates previously discussed are conservative upper limits, the 0 to $3 \mathrm{~km}$ discrepancies clearly fall outside the combined uncertainty range for any realistic uncertainty scenario. Although these discrepancies do fall within the combined systematic error estimates (as discussed in Appendix A

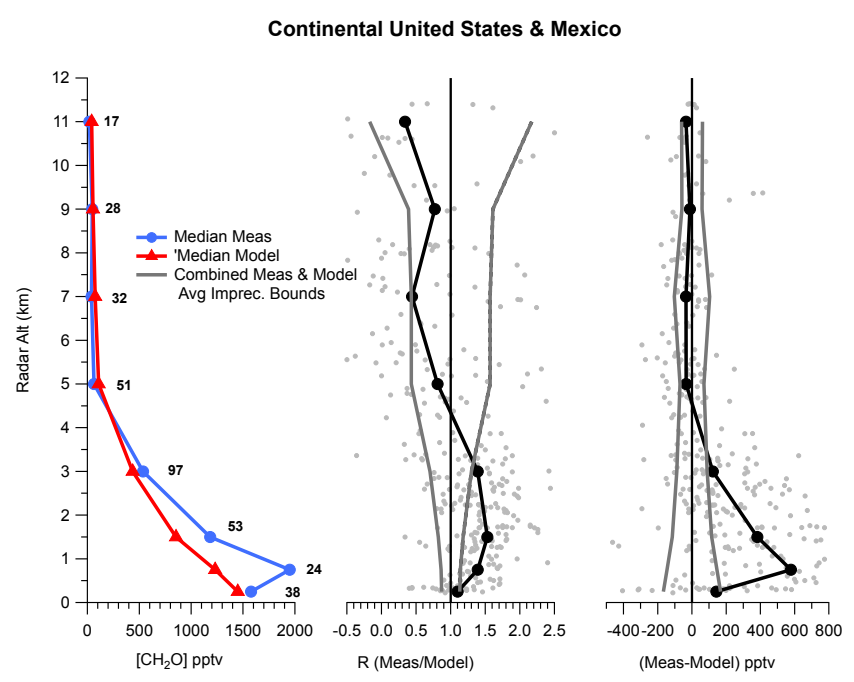

Fig. 5. Time coincident radar altitude bin TDLAS measurement (Meas)-box model (Model) comparisons on the hydrocarbon time base over the continental United States and Mexico (exclusive of Mexico City and Monterrey) during both phases of INTEX-B. The center plot shows the median point-to-point measurement/model ratios for each altitude bin (dark circles) while the right side plots the median point-to-point measurement-model differences (dark circles). Individual ratios and differences are shown by the light gray points. The solid gray lines refer to the combined average bin ratio and bin difference measurement and model uncertainties at the $2 \sigma$ level using measurement imprecision and model constraint uncertainty estimates described in the text. The numbers next to each point on the left plot are the number of points in each bin.

these estimates range between 34 and $68 \%$ at the equivalent $2 \sigma$ level), which also includes instrumental systematic error estimates and model kinetic parameter uncertainty estimates, the boundary layer comparisons of Fig. 5 as well as those in Figs. 4-7, clearly indicate measurement-box model differences that are systematic in nature. The systematic model uncertainty must also include terms associated with wrong and/or incomplete chemistry, but the estimates above do not include this.

The Mexico City and Monterrey plots of Fig. 6 likewise show model underestimations between 0.5 to $2 \mathrm{~km}$, and agreement in the lowest altitude bin. At altitudes from $3 \mathrm{~km}$ and greater all 3 plots of Fig. 6 show measurement-model agreement within or just lying on the combined uncertainty bounds. The Gulf of Mexico data of Fig. 7 shows model underestimates for all three low-altitude bins up to $2 \mathrm{~km}$. As will be discussed later, only about $12 \%$ of these points originate from Mexico City outflow. In the $2-4 \mathrm{~km}$ bin, the median ratio and median difference values are very close to the mutual uncertainty bound yet the median measurement and model values on the left indicate perfect agreement. This is a case where the point-to-point comparisons reveal a potential problem in our understanding but is hidden by the 

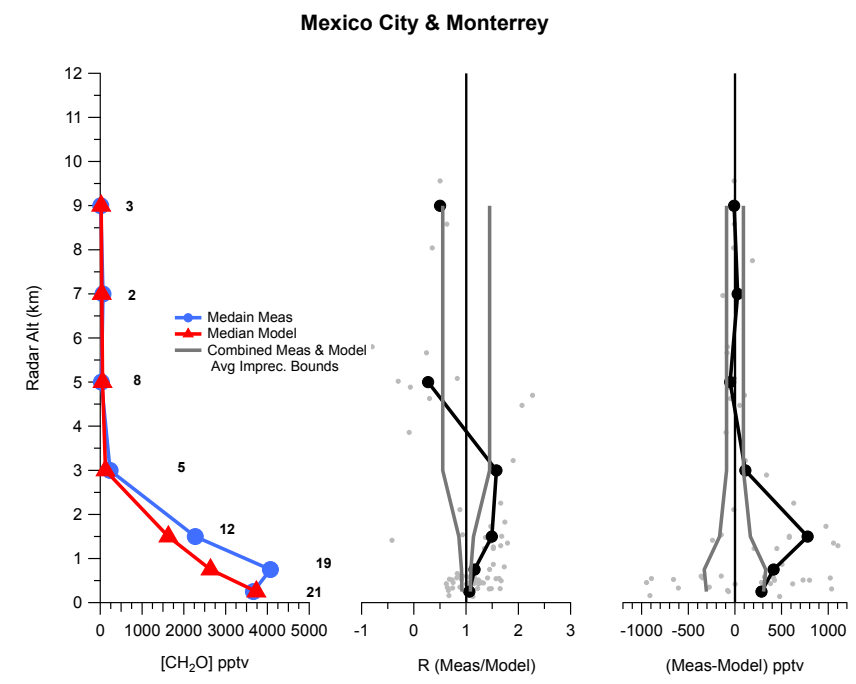

Fig. 6. Time coincident comparisons on hydrocarbon time base over Mexico City and Monterrey during the 1st phase of INTEX-B. This plot has the same format as Fig. 5. The outlier ratio between 6 and $8 \mathrm{~km}(R=4.7)$ is an artifact of the small number of points (2) and was omitted from the center plot to preserve resolution but was kept in the difference plot since the difference was small. The combined imprecision limits could not be determined for the 4-6, 6-8, and $8-10 \mathrm{~km}$ bins and thus the values for the $2-4 \mathrm{~km}$ bins are repeated here for the higher altitude bins.

simple comparison of medians, and this emphasizes the importance of employing all three comparison plots when assessing measurement-model agreement. Like the previous figures, at higher altitudes than $4 \mathrm{~km}$ the measurements and model values are in agreement for all three plots.

The Pacific Ocean plots of Fig. 8 show excellent measurement-model agreement in the medians over all altitude bins, despite individual comparisons falling outside the estimated mutual uncertainty limits. This figure provides further evidence supporting the conclusions of past studies: namely, that in the remote background atmosphere away from local sources and sinks where $\mathrm{CH}_{4}$ oxidation is the prevalent source of $\mathrm{CH}_{2} \mathrm{O}$ we generally have a good understanding of $\mathrm{CH}_{2} \mathrm{O}$ chemistry, despite larger measurement variance than modeled (Fried et al., 2003b). By contrast, the systematic discrepancies observed in the boundary layer over the continental United States, Mexico and the Gulf of Mexico, suggests that as in past studies, one or many of the aforementioned issues presented in the Introduction may be operative.

Figure 9 further examines the boundary layer discrepancies during the 1st phase as a function of geographical location. Here the measurements on the hydrocarbon time base are colored and sized by the measured mixing ratios. To preserve resolution this scale only extends up to $6000 \mathrm{pptv}$. However, there are plumes over the Gulf of Mexico and over Mexico City that extend up to 14.6 ppbv. It should be

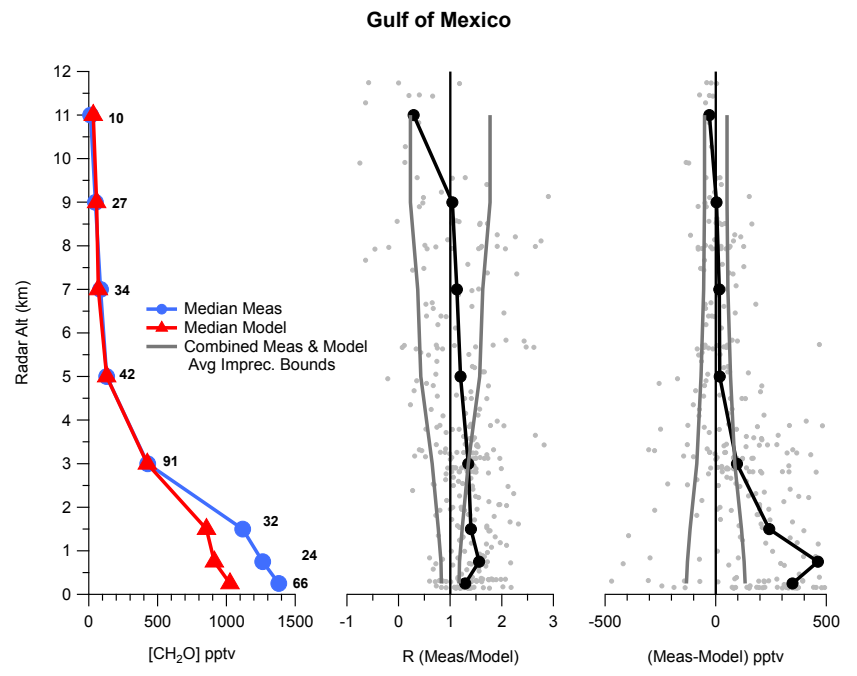

Fig. 7. Time coincident comparisons on hydrocarbon time base over the Gulf of Mexico during the 1st phase of INTEX-B. This plot has the same format as Fig. 5. The combined imprecision limits could not be determined for the $10-12 \mathrm{~km}$ bins (only 1 data point) and the values for the $8-10 \mathrm{~km}$ bins are repeated for that bin.

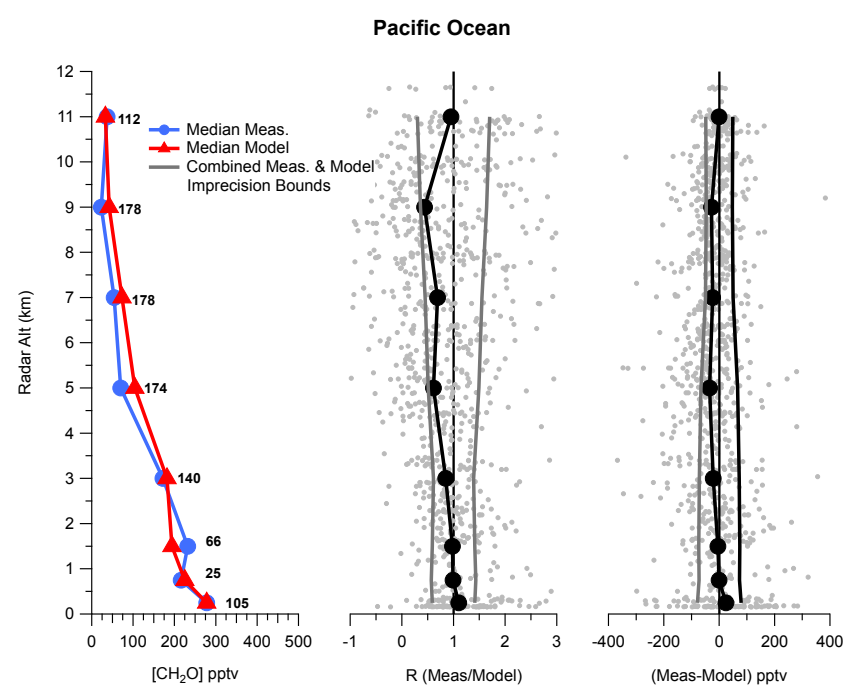

Fig. 8. Time coincident comparisons on hydrocarbon time base over the Pacific Ocean during the 2nd phase of INTEX-B. This plot has the same format as Figs. 5-7.

noted that these measurements are averaged on the hydrocarbon time base, which is typically on the order of $1 \mathrm{~min}$ or more. Peak plume durations, however, are only seconds to 10 's of seconds long, and thus true ambient $\mathrm{CH}_{2} \mathrm{O}$ mixing ratios can be significantly higher than those in Fig. 9. For example, our 1 -s measurements indicate that the $14.6 \mathrm{ppbv}$ Mexico City plume attains values as high as 28.6 ppbv. We also plot in Fig. 9 the various point VOC emission sources (sized by their VOC emission rates in tons $\mathrm{yr}^{-1}$ ) as well 


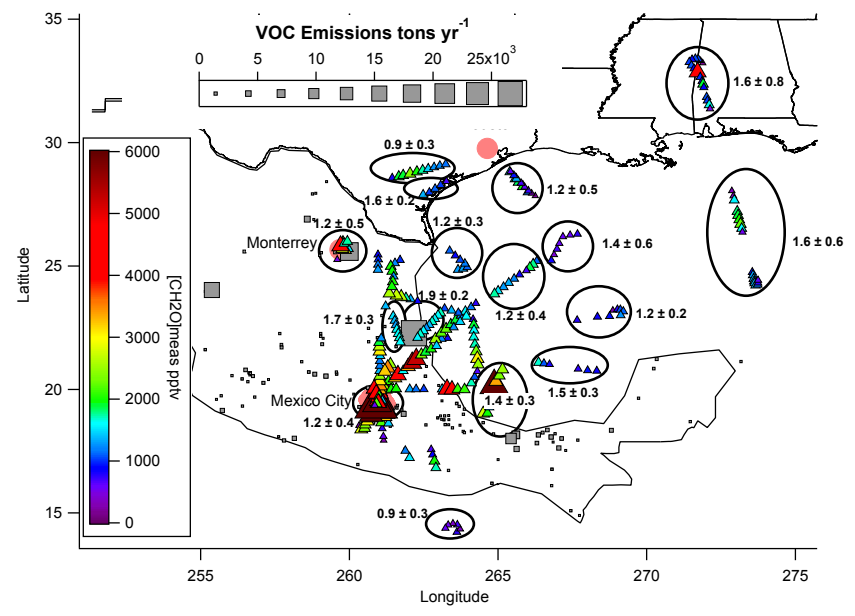

Fig. 9. Boundary layer (radar altitude $<2 \mathrm{~km}$ ) $\mathrm{CH}_{2} \mathrm{O}$ TDLAS measurements on the hydrocarbon time base during 1 st phase of INTEX-B. Mixing ratios (triangles) are colored and sized by their values. To preserve resolution the mixing ratio scale extends to only 6 ppbv. Several measurements are greater than this, including: (1) a large plume over the Gulf of Mexico (lat. = 20.2, long. $=264.9, \mathrm{CH}_{2} \mathrm{O}=9 \mathrm{ppbv}$ ); (2) and numerous points over Mexico City extending up to $\mathrm{CH}_{2} \mathrm{O}$ values of $14.6 \mathrm{ppbv}$. The filled gray squares show VOC point sources sized by their emission values in tons $\mathrm{yr}^{-1}$. Measurements, which are grouped into geographic flight segments (see text), are highlighted by circles. The average and standard deviation of the measurement/box model ratios for each flight segment are given adjacent to each circle. The Tampico VOC emission (latitude $=22.3$, longitude $=262.2$ ) is 27700 tons $\mathrm{yr}^{-1}$, which is more than the sum of the largest 78 Mexico City VOC emissions (sum $=27024$ tons $\mathrm{yr}^{-1}$ ).

as average measurement/model ratios and standard deviations for various geographic flight segments (data close in time and geographic location) highlighted in circles. It is useful to keep in mind that the median value for the combined estimated measurement-model ratio uncertainty in the boundary layer is 0.13 , and thus many of the averaged ratios over these domains are systematically high. As discussed in Appendix A, the combined measurement-model uncertainty (measurement precision combined with the model constraint uncertainty) for both the differences and ratios are calculated for every comparison point on the hydrocarbon time base.

Over Mexico City and Monterrey, the averaged flight segment measurement/model ratios in the boundary layer are 1.2 while the ratios over the Gulf are primarily in the 1.2 to 1.4 range; indicating small to modest model underestimates on average over these regions. Near the largest VOC emission sources northeast of Mexico City and over Western Alabama (several h downwind of a large power plant), the flight segment ratios are in the 1.6 to 1.9 range; indicating larger model underestimates. By contrast, over parts of Texas and the Pacific Ocean side of Mexico the ratios are closer to unity. Although Fig. 9 provides a general sense where larger measurement-model discrepancies are observed, it does not provide further information regarding the cause of such discrepancies other than the fact that the largest discrepancies do not in general correlate with the highest $\mathrm{CH}_{2} \mathrm{O}$ mixing ratios. In fact, the measurement-model ratios of Fig. 10 show more clearly that better agreement tends to be obtained at higher ambient $\mathrm{CH}_{2} \mathrm{O}$ mixing ratios. This plot displays the median and averaged measurement-model ratios binned by model values for both the boundary layer (colored filled points) and outside the boundary layer (open black circles). In the boundary layer the medians are colored and sized by the median alkene production percentage from the model, and the numbers next to each point represent the number of points in the bin (top number) and the binned median photochemical age (bottom number). The photochemical age was determined from the ratio of 2-butyl nitrate to butane, as discussed by Bertman et al. (1995) and Perring et al. (2010). This age determination will hereafter be referred to as butane time or photochemical age. In these age calculations, we employ the instantaneous measured DC-8 OH mixing ratios using the laser induced fluorescence technique (Ren et al., 2008; Mao et al., 2009). Although there is more uncertainty in the precise photochemical age for more aged air using instantaneous $\mathrm{OH}$ values, this procedure still yields correct relative ages. The gray shaded region represents the median for the combined measurement (random uncertainty) and model constraint uncertainty at the $2 \sigma$ limits in the $\mathrm{CH}_{2} \mathrm{O}$ ratio for the boundary layer $( \pm 13 \%)$, as discussed previously. Binned values inside this band fall within the expected uncertainty limits.

As Fig. 10 shows, the median boundary layer measurement-model ratios in the lowest four model mixing ratio bins ( 0 to 2000 pptv) yield high values extending from 1.28 to 1.46 , and these fall outside the described uncertainty limits. Although not shown, the first four model bins yield median (measurement-model) differences in the point-to-point comparisons from $164 \mathrm{pptv}$ to $517 \mathrm{pptv}$. The alkene production percentage extends from 4 to $20 \%$ for these points while the binned median photochemical age ranges between 42 and $14 \mathrm{~h}$. The 3 highest model binned non-boundary layer points (500-2000 pptv) show discrepancies comparable to those in boundary layer and this is to be expected since the binned median altitudes for these points, which are primarily over the Gulf of Mexico and Mexico, (radar altitudes of 2.4 to $2.8 \mathrm{~km}$ ) are all close to our $2 \mathrm{~km}$ boundary layer cutoff and $\sim 60 \%$ of these comparisons are from outflow events from the Mexico City boundary layer (to be discussed); Figs. 5-7 further show that measurement-model discrepancies over these two regions are actually observed over a range of altitudes below and slightly above our $2 \mathrm{~km}$ boundary layer cutoff. By contrast, the 5 lowest model non-boundary layer binned points spanning the 0 to 500 pptv range yield measurementmodel agreement to within $13 \%$ (median radar altitudes are all above $3 \mathrm{~km}$ ) and only $7 \%$ of these comparisons 


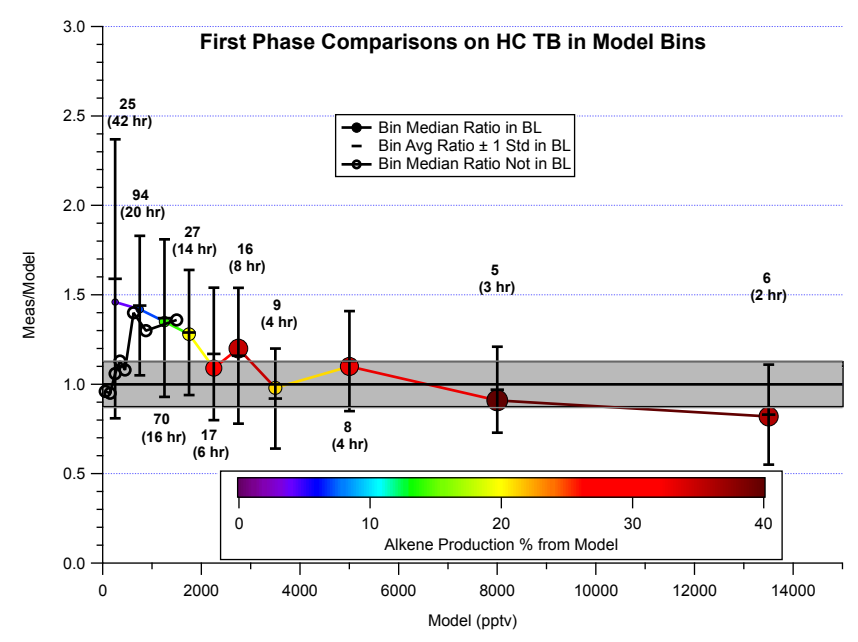

Fig. 10. TDLAS measurement/model ratios for all locations during first phase on hydrocarbon time base (HC TB) binned by model values as a function of model values. Each point displays the bin average ratio (horizontal lines), the \pm 1 standard deviation for this bin (bars), and the median ratio (circles). The filled colored points are in the boundary layer (BL, radar altitude $<2 \mathrm{~km}$ ) while the open black circles are outside the BL. Each BL point is colored and sized by the bin median alkene production percentage of $\mathrm{CH}_{2} \mathrm{O}$ from the model. The number of data points in each bin is given by the top number next to each point while the bottom number represents the binned median value for the photochemical age determined from the ratio of 2-butyl nitrate to butane (see Perring et al., 2010) employing the instantaneous measured $\mathrm{OH}$ concentrations. The gray shaded region represents the median for the combined measurement and model $2 \sigma$ uncertainty limits $( \pm 13 \%)$ in the boundary layer.

are from Mexico City boundary layer outflow events. The 3rd model non-boundary layer point spanning the 200 to 300 -pptv range yields agreement (median bin ratio $=1.06$, $N=32$, median radar altitude $=3.3 \mathrm{~km}$ ) while its boundary layer counterpart spanning the 0 to $500 \mathrm{pptv}$ shows a large measurement-model discrepancy (median bin ratio $=1.46$, $N=25$, median radar altitude $=1.3 \mathrm{~km}$ ). It is thus apparent that the higher altitude binned data outside the boundary layer reflects entirely different behavior than within the boundary layer. It is interesting to note that the boundary layer discrepancies observed here with ambient $\mathrm{CH}_{2} \mathrm{O}$ mixing ratios starting at values around 250 to $500 \mathrm{pptv}$ are consistent with our TRACE-P (Fried et al., 2003b) and INTEX-NA (Fried et al., 2008a) results; in these cases discrepancies were observed when binned model values exceeded mixing ratios of $\sim 350$ pptv.

However, as Fig. 10 suggests, there are additional factors at play when ambient $\mathrm{CH}_{2} \mathrm{O}$ mixing ratios exceed $\sim 2$ ppbv; here median binned alkene $\mathrm{CH}_{2} \mathrm{O}$ production percentages increase to values greater than $28 \%$ and median processing times are less than $6 \mathrm{~h}$. Although methane oxidation dominates $\mathrm{CH}_{2} \mathrm{O}$ production in the boundary layer for the 4 lowest mixing ratio bins, production from alkenes and $\mathrm{RCO}_{3}$-type compounds (PAN and higher acetyl peroxy compounds) becomes dominant in the model for the six highest mixing ratio bins. The observed alkene sources of $\mathrm{CH}_{2} \mathrm{O}$, which are comprised of ethene, propene, isoprene, 1-butene, trans-2-butene, cis-2-butene, and 1,3-butadiene, is dominated in all cases by $\mathrm{CH}_{2} \mathrm{O}$ production from ethene. Starting at the 5 th boundary layer model bin (model midpoint $=2250 \mathrm{pptv}$ ) and extending to the highest model mixing ratio bin, over $80 \%$ of the alkene production of $\mathrm{CH}_{2} \mathrm{O}$ originates from ethene. This is consistent with the ground-based measurements reported by Apel et al. (2010) at the $\mathrm{T}_{0}$ site where ethene was found to comprise $65 \%$ of the total alkenes listed above on a 24-h basis throughout the month of March. As can be seen in Fig. 10, the six highest model bins result in measurement-model ratios near or within the uncertainty band, and under these conditions the observations included as model inputs appear to accurately represent the dominant ambient chemistry that controls $\mathrm{CH}_{2} \mathrm{O}$ production. However, a closer look shows that for the highest model bin, the model slightly overpredicts the observations by up to $18 \%$. This suggests that very close to large sources of non-methane-hydrocarbons, NMHCs, (primarily ethene), the model's diurnal steady state assumption appears to be inadequate, resulting in significant overpredictions of $\mathrm{CH}_{2} \mathrm{O}$ generated from ethene. While the steady state model is not expected to be able to accurately calculate $\mathrm{CH}_{2} \mathrm{O}$ under non-steady-state conditions, it is instructive to examine the non-steady-state influences in closer detail. Further downwind of pollution sources, where the fast-reacting ethene has largely decayed away, the model underpredicts the observed $\mathrm{CH}_{2} \mathrm{O}$. Thus, in the vicinity of high ethene sources, nonsteady state conditions can result in different measurementmodel behavior depending upon the processing time, and this will be further discussed in the next section. At low mixing ratios, by contrast, the measurement/model ratios of Fig. 10 suggest the influence of the other effects raised in the Introduction. These effects are apparently masked when fast $\mathrm{CH}_{2} \mathrm{O}$ production from ethene and $\mathrm{RCO}_{3}$-type compounds (PAN and higher acetyl peroxyl compounds) becomes dominant in the vicinity of fresh plumes.

Considering only points with low contributions to total $\mathrm{CH}_{2} \mathrm{O}$ production from ethene (production $<12 \%$ ), the average and median measurement/model ratio of $\sim 1.2$ previously discussed in connection with Fig. 9 in the Mexico City boundary layer reduces to 0.96 . Although this restricted comparison is based on only 10 points, it indicates that the model accurately reproduces the observations in the boundary layer over Mexico City and that unmeasured hydrocarbons and direct $\mathrm{CH}_{2} \mathrm{O}$ emissions from vehicle traffic have minimal effect on the predicted $\mathrm{CH}_{2} \mathrm{O}$ in this case. Although this appears to contradict our earlier findings in connection with Fig. 6, the discussion of the temporal behavior of $\mathrm{CH}_{2} \mathrm{O}$ in the next section will shed more light on this topic. The reduced importance of vehicular traffic on our $\mathrm{CH}_{2} \mathrm{O}$ observations can only come about if the observed $\mathrm{CH}_{2} \mathrm{O}$ over the city is primarily from oxidation of 
$\mathrm{CH}_{2} \mathrm{O}$ precursors, as the model does not include direct $\mathrm{CH}_{2} \mathrm{O}$ emission sources. This is consistent with the fact that local sampling times for DC-8 overflights in the Mexico City boundary layer took place outside of rush hour time periods (11:29-14:20 on Monday-Saturday), when source apportionment studies find $\sim 80$ to $99 \%$ of ambient $\mathrm{CH}_{2} \mathrm{O}$ is from secondary sources (Garcia et al., 2006; Volkamer et al., 2010). The importance of secondary $\mathrm{CH}_{2} \mathrm{O}$ is further corroborated from our fast (1-s) $\mathrm{CH}_{2} \mathrm{O}$ correlations with $\mathrm{CO}_{2}$, which produce regression slopes with factors of 3-4 times higher than those measured by Herndon et al. (2005) during ground-based vehicular traffic ("vehicle chase") studies in Mexico City. We can further use the median photochemical age as well as the median $\mathrm{CH}_{2} \mathrm{O}$ lifetime to eliminate the possibility that direct $\mathrm{CH}_{2} \mathrm{O}$ emissions are responsible for most of the measurement-model disparities in the four lowest boundary layer bins of Fig. 10. In these bins, $91 \%$ of the comparisons were either over the Gulf of Mexico (54\%) or over continental Mexico and/or the United States (37\%) outside of major urban centers. The median photochemical age was at least $14.8 \mathrm{~h}$ for these points, which when compared to a median $\mathrm{CH}_{2} \mathrm{O}$ lifetime of $2.4 \mathrm{~h}$ indicates that any direct $\mathrm{CH}_{2} \mathrm{O}$ emissions would have decayed to values well below the observed discrepancies (less than $0.2 \%$ of primary emission remaining). We will return to discussion of the boundary layer discrepancies of Fig. 10 for mixing ratios $<2$ ppbv after we discuss the temporal behavior of fresh boundary layer plumes with much higher mixing ratios.

At typical DC-8 overpass times over the City, the photolysis of secondary VOC oxidation products including $\mathrm{CH}_{2} \mathrm{O}$ is responsible for $\sim 52 \%$ of overall $\mathrm{HO}_{\mathrm{x}}$ production (Volkamer et al., 2010), and for an even higher percentage on a daytime average basis (Dusanter et al., 2009; Volkamer et al., 2010). Primary emissions of $\mathrm{CH}_{2} \mathrm{O}$ (Herndon et al., 2005; Garcia et al., 2006) are most relevant to sustain photochemical activity in the mid-morning (Lei et al., 2009; Volkamer et al., 2010), but become dominated by secondary $\mathrm{CH}_{2} \mathrm{O}$ sources over aging time scales of few hours (Garcia et al., 2006; Volkamer et al., 2010). This emphasizes the relevance of secondary sources of pollution to sustain the production of ozone and SOA already in the chemical near field over Mexico City.

\section{Temporal behavior of $\mathrm{CH}_{2} \mathrm{O}$ in fresh boundary layer plumes}

The temporal behavior of $\mathrm{CH}_{2} \mathrm{O}$ observations in fresh boundary layer plumes in the presence of high ethene mixing ratios and where precursor values are rapidly changing cannot be adequately reproduced using diurnal steady state (DSS) modeling assumptions. However, an examination of the inadequacies of such a modeling approach can highlight dominant processes leading to $\mathrm{CH}_{2} \mathrm{O}$ production in such environments. As will be shown, the DSS box model systematically overestimates observations of $\mathrm{CH}_{2} \mathrm{O}$ in plumes very close to emission sources high in ethene. The DSS assumption constrains values of ethene to the instantaneous observed value at the time of the DC- 8 measurement and assumes this value throughout the model day, resulting in model overestimates of $\mathrm{CH}_{2} \mathrm{O}$. At sustained very high ethene concentrations, the model will significantly overestimate concentrations of product species with moderate lifetimes, such as acetaldehyde and higher aldehydes. In essence, it takes a finite amount of time for the model to properly spin-up. As the plume age approaches the ethene lifetime (around 3-7 h over Mexico City), the model starts to underestimate the observations of $\mathrm{CH}_{2} \mathrm{O}$. This latter effect is a result of another perturbation due to non-steady-state conditions: namely, it reflects the fact that the instantaneous measurement of ethene used in the box model does not account for the temporal history of $\mathrm{CH}_{2} \mathrm{O}$ recently produced by the rapidly decaying ethene. For intermediate processing times close to the $\mathrm{CH}_{2} \mathrm{O}$ lifetime one would expect the measurement-model to cross the value of one.

Figure 11a displays one such example of the temporal dependence of the $\mathrm{CH}_{2} \mathrm{O}$ measurement/model relationship due to ethene for various plume ages. This figure shows a time series plot of the $\mathrm{CH}_{2} \mathrm{O}$ measurements and model results along with corresponding $2 \sigma$ uncertainty limits. These data were acquired over the center of Mexico City on 16 March 2006 where back trajectory analysis indicated that the sampled air at the peak mixing ratio was approximately $2 \mathrm{~h}$ downwind of two of the largest VOC emission sources in the center of the city (a facility that manufactures industrial food packaging and one that makes polyester additives). Some of the points in Fig. 11a comprise points in the highest model bins of Fig. 10. We designate above each point in Fig. 11a the measurement/model ratio and the photochemical age. It is important to note that the 2.2-h age from this analysis is in agreement with back trajectory analysis (see Martin et al., 2003 for a discussion of this approach). The $\mathrm{CH}_{2} \mathrm{O}$ observations in Fig. 11a are also colored and sized by the ethene production percentage from the box model. The behavior in this figure, with a few exceptions, is in line with the expectations discussed above. Figure $11 \mathrm{~b}$ better displays this behavior for these same points by plotting the measurement/model ratio as a function of photochemical age. The 15 points most influenced by $\mathrm{CH}_{2} \mathrm{O}$ production from ethene (photochemical age $\leq 6.1 \mathrm{~h}$ and ethene production percentage $\geq 12 \%, N=15$ ) are emphasized by their color and size and are fit using a 3term polynomial shown in blue (Profile 1). A linear fit, which would be equally valid, yields essentially the same behavior with some small differences. Boundary layer flight legs over central Mexico City on other days are very similar with only slightly different shapes and intercepts, dictated by the ethene and $\mathrm{CH}_{2} \mathrm{O}$ lifetimes.

The red curves in this figure represent results from an exercise that tests the box model steady state assumption against output from a Lagrangian model that simulates nonsteady state chemistry in a plume with rapidly decaying ethene. The Lagrangian model was initialized using values 


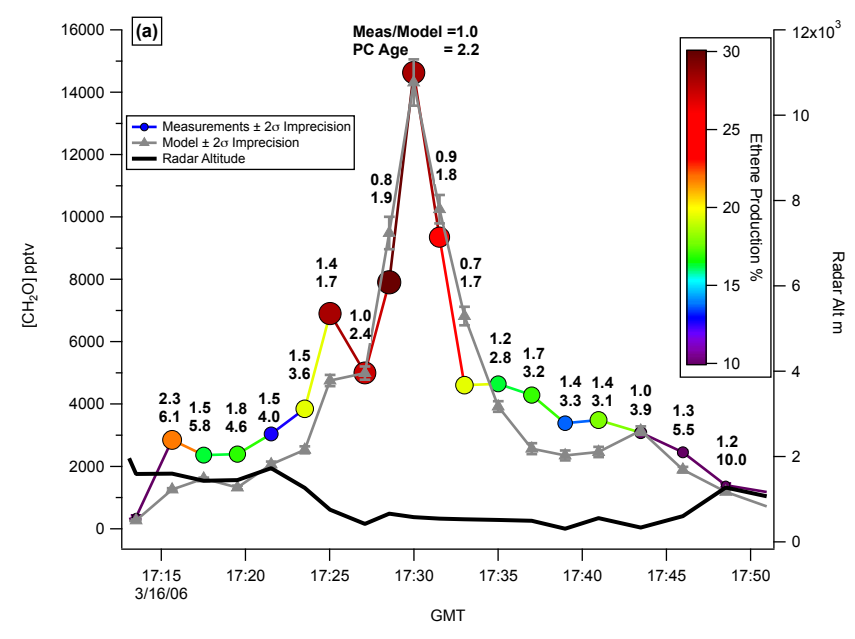

Fig. 11a. TDLAS measurement and model time series on the hydrocarbon time base during a flight segment in the boundary layer over the central part of Mexico City on 16 March 2006 downwind of two large VOC emitting facilities. The $2 \sigma$ measurement and model uncertainties are shown with each data point by the error bars (the measurement error bars are smaller than each point size). The measurements are colored and sized by the ethene production percentage from the box model. The numbers above each comparison point represent the measurement/model ratio (upper number) and the photochemical age (PC Age, hours) derived from the ratio of 2-butyl nitrate to butane (Bertman et al., 1995; Perring et al., 2010) employing instantaneous measured $\mathrm{OH}$ concentrations on the DC8. The solid black line shows the radar altitude (right hand y-axis).

observed on the DC8, and then a "pulse" of NMHCs was introduced to simulate an emission source. The chemistry was allowed to evolve in a Lagrangian, time-dependent fashion with all model constraints relaxed. The calculations assumed a concurrent "pulse" of $\mathrm{NO}_{\mathrm{x}}$ and various $\mathrm{NO}_{\mathrm{x}}$ mixing ratios from 0 to $25 \mathrm{ppbv}$ were assumed. The "pulse" value of NMHCs was set equal to their observed values at the peak of Fig. 11a (ethene (8.8 ppbv), isoprene (53 pptv), and other alkenes (1360 pptv)) on 16 March 2006 and were introduced into the model in the morning at sunrise. Output from the Lagrangian model was then taken at various times, and fed into the steady-state box model to test the fidelity of the steady-state approach under various plumeprocessing times. The ratio of the Lagrangian to steady state box model $\mathrm{CH}_{2} \mathrm{O}$ is plotted as a function of these processing times on the same axis as the measurement-model comparisons. The Lagrangian-to-steady state ratios serve as a proxy for the measurement/model ratios in indicating the influence of non-steady-state conditions. The spread in these results, given by the red bounds for the two curves, represent the maximum and minimum in these calculations for the various $\mathrm{NO}_{\mathrm{x}}$ scenarios. This plot simulates the behavior of the box model in calculating $\mathrm{CH}_{2} \mathrm{O}$ when sampling a large time dependent ethene plume in the near-field, in this case from factory sources. Only slightly different behavior is observed

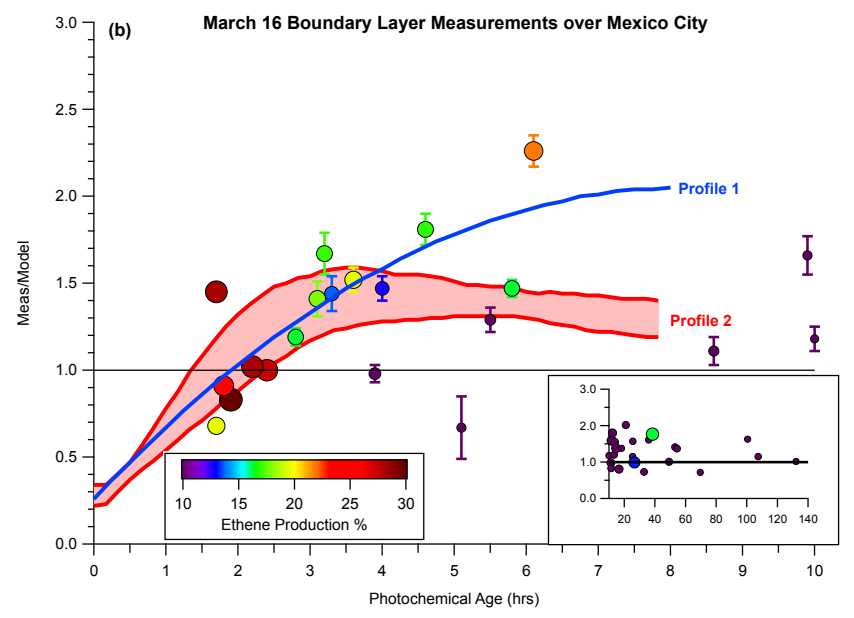

Fig. 11b. TDLAS measurement/model ratios as a function of photochemical age for the same data shown in Fig. 11a (16 March 2006), which are colored and sized by the ethene production percentage. The error bars are the combined $2 \sigma$ measurement-model imprecision limits. The blue curve (Profile 1) is a 3-term polynomial regression fit of 15 data points (photochemical age $\leq 6.1 \mathrm{~h}$ and ethene production percentage $\geq 12 \%$ ). The red profiles display the expected behavior of the box model using a Lagrangian model to simulate the time dependent behavior due to various VOC emissions in the morning (see text) in the presence of variable $\mathrm{NO}_{\mathrm{x}}(0$ to $25 \mathrm{ppbv}$ ). The ratio of the Lagrangian to box model $\mathrm{CH}_{2} \mathrm{O}$ is plotted as a function of photochemical age. At processing times longer than $\sim 6 \mathrm{~h}$ and/or lower ethene emission percentages, other sources of $\mathrm{CH}_{2} \mathrm{O}$ become dominant and these are displayed by the inset, which utilizes the same axes as the main plot. A linear fit of the inset points yields: intercept $=1.35 \pm 0.1$, slope $=-0.002, r^{2}$ of 0.02 .

when the ethene spike is introduced at different times of the day. We designate the bounded red curves as Profile 2.

Although there are clear differences between the two profiles, there are also some important similarities. At zero processing time, the simulations of Profile 2 span the Yintercept value of Profile $1(0.26 \pm 0.47)$, and the photochemical age where 1:1 measurement/model agreement is obtained in Profile $1(\sim 2.0 \mathrm{~h})$ is spanned by the range of values from Profile 2. In fact, we observe the expected measured/model $\mathrm{CH}_{2} \mathrm{O}$ behavior as a result of non-steady-state conditions out to $\sim 4 \mathrm{~h}$ of processing with ratios approaching 1.6. Thus, in fresh ethene dominated plumes one must recognize such time-dependent behavior where one can obtain steady-state model overestimations, underestimations, and agreement with the observations depending upon the processing time. Although the curvature will be different for different alkene emission rates, one should expect very similar behavior to Fig. 11b. This behavior explains the measurement/model ratios for the largest 6 model bins of Fig. 10 as a result of non-steady state conditions. At processing times longer than $\sim 4 \mathrm{~h}$, the two profiles of Fig. 11b show 
differences; here the observations to box model ratios continue to rise compared to the Lagrangian time dependent simulations, which level off and start to decay as the influence of fast reacting alkenes abates. These differences most likely reflect the additional influence of dilution, additional hydrocarbon sources of $\mathrm{CH}_{2} \mathrm{O}$, which become more important as the plume ages, and the imperfect atmospheric simulation here using the simple Lagrangian model. Although not as obvious as the 15 points in Fig. 11b, the effects of ethene are still seen in the Lagrangian/box model simulations out to processing times as long as $\sim 12 \mathrm{~h}$ for these simulations (ethene lifetime here $=6.8 \mathrm{~h}$ ). At much longer processing times and/or low ethene production contributions, as shown by the inset and the additional 5 points of Fig. $11 \mathrm{~b}$ (the 5 points with very low ethene production percentages that do not fall within the confines of Profile 2), the effects of ethene are no longer evident for this 16 March plume.

\section{Mexico City outflow and evidence for unmeasured hydrocarbons and multi-generation $\mathrm{CH}_{2} \mathrm{O}$ oxidation processes}

Thus, although we can explain the $\mathrm{CH}_{2} \mathrm{O}$ TDLAS measurement-model relationships as an artifact of the steady state assumption for short transport times where ethene production dominates, this cannot explain the boundary layer behavior of Figs. 9-11 whenever the transport times exceed $\sim 8 \mathrm{~h}$ and where other sources of $\mathrm{CH}_{2} \mathrm{O}$ other than ethene may dominate. Many of the Gulf boundary layer legs of Fig. 9 are examples of this and Fig. 10 further hints at the importance of photochemical age. In this section we focus our discussion on Mexico City outflow events in order to further examine $\mathrm{CH}_{2} \mathrm{O}$ measurement-model relationships as a function of plume age. In addition to showing the influence of Mexico City emissions on $\mathrm{CH}_{2} \mathrm{O}$ budgets and hence on $\mathrm{HO}_{\mathrm{x}}$ radical budgets downwind, this analysis also attempts to elucidate the production mechanisms of $\mathrm{CH}_{2} \mathrm{O}$ in an aging plume when the non steady-state influences of local sources are minimized. Although we can carry out this same analysis for all boundary layer plumes, including the myriad of plumes originating from Gulf oil platforms and production facilities, restricting this to Mexico City boundary layer outflow plumes has two main advantages: (1) the input hydrocarbons are better characterized since we have available the Mexico City network of fully instrumented sampling sites ( $T_{0}, T_{1}$, and $T_{2}$ ) as further discussed by Apel et al. (2010), and (2) the characteristics of these outflow plumes can be further explored to ensure that fresh local pollution sources do not have large impacts on the plume composition as the plume ages. Although individual outflow comparison points can indeed be affected by such local sources, the binning procedure on average reduces such influence.

Mexico City plumes were identified using the same approach as Perring et al. (2010). In this case we employed the official 1-min merged data set instead of the merge on the hydrocarbon time base. As discussed by Perring et al. (2010), back trajectories were used to select data that passed within $\sim 100$ miles (1.5 degrees) of the $T_{0}$ sampling site in the center of Mexico City at pressures higher than $680 \mathrm{mb}$, which corresponds to an elevation of $\sim 1 \mathrm{~km}$ above the ground over Mexico City (Mexico City elevation is $2240 \mathrm{~m}$ and the typical surface pressure is $\sim 770 \mathrm{mb}$ ). Of the 422 time periods identified by Perring, 262 time periods had simultaneous $\mathrm{CH}_{2} \mathrm{O}$ TDLAS measurements and model results where there were also calculations of photochemical age. In these calculations a diurnally averaged $\mathrm{OH}$ concentration of $3 \times 10^{6}$ molecules $\mathrm{cm}^{-3}$ was assumed. Figure 12 depicts DC- 8 intercepts of these outflow events colored and sized by the photochemical age, with the Mexico City area considered highlighted in the square. The majority of these plume outflows (69\%) were intercepted by the DC-8 at radar altitudes $\leq 2 \mathrm{~km}$. Like Fig. 9, the solid gray squares show VOC point sources sized by their emission values in tons $\mathrm{yr}^{-1}$. Many of these plume intercepts and/or their back trajectories did not pass near these sources.

Figure 13 shows the resulting $\mathrm{CH}_{2} \mathrm{O}$ measurement and model behavior for these Mexico City outflow plumes as a function of photochemical age. Although there is some uncertainty in the photochemical age clock due to a number of causes (assuming a single diurnally averaged $\mathrm{OH}$ mixing ratio to represent processing over different time scales, neglecting the effects of dilution on the $\mathrm{OH}$ mixing ratios as the plume ages, and resetting of the photochemical clock as a result of mixing in air masses with different butyl nitrate to butane time histories), Perring et al. (2010) find that the photochemical ages in the first two days are similar to transport times calculated from observed wind speeds. Employing back trajectories for these same Mexico City outflow events, we find similar general agreement: back trajectory times agree with the photochemical age to within $\pm 5 \mathrm{~h}$ for butane times between 7.5 and $32.5 \mathrm{~h}$. At shorter times there is ambiguity in the back trajectory determination of air mass origin relative to the butane clock since we do not have a precise location for the start of the butane clock. At longer times the butane times appear to be influenced by local inputs, which reset the butane time to lower values. The discussion, which follows, will primarily focus on outflow events in the above time range.

Figure 13 displays the fractional enhancement over background for $\mathrm{CH}_{2} \mathrm{O}$ measurements, box model values, and $\mathrm{CO}$ for various plume age bins. This plot, which is similar to that displayed by Perring et al. (2010) for various species, shows the growth of $\mathrm{CH}_{2} \mathrm{O}$ relative to $\mathrm{CO}$ as the plume ages. The fractional enhancement (FE) for each is calculated from:

$\mathrm{FE}=\left(X-X_{\mathrm{bkg}}\right) /\left(X_{\text {inital }}-X_{\mathrm{bkg}}\right)$

Here $X$ represents the mixing ratios for each point where there were $\mathrm{CH}_{2} \mathrm{O}$ measurements (or $\mathrm{CO}$ measurements), model values, and age determinations; $X_{\mathrm{bkg}}$ are the 


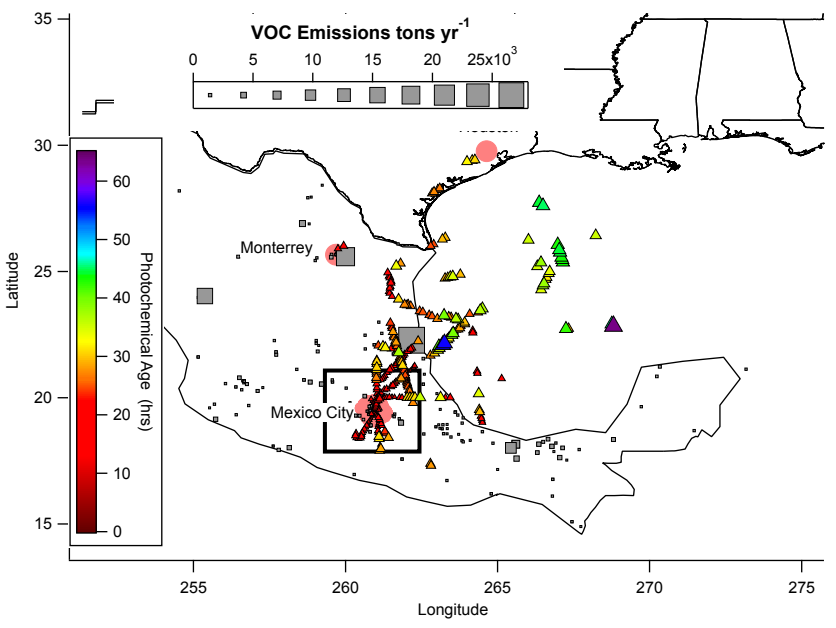

Fig. 12. Mexico City outflow events (1-min merged time base) based upon criteria discussed in text colored and sized by photochemical age from the ratio of 2-butyl nitrate to butane (Bertman et al., 1995; Perring et al., 2010). As in Fig. 9, the solid gray squares show VOC point sources sized by their emission values in tons $\mathrm{yr}^{-1}$. The black square denotes the approximate limit for the region we define as the Mexico City area.

background concentrations observed at the longest photochemical times over the Gulf $\left(\left[\mathrm{CH}_{2} \mathrm{O}\right]_{\text {TDLAS meas }}=572 \mathrm{pptv}\right.$, $\left[\mathrm{CH}_{2} \mathrm{O}\right]_{\text {model }}=522 \mathrm{pptv}$, and $\left.[\mathrm{CO}]=113 \mathrm{ppbv}\right) ;$ and $X_{\text {inital }}$ are the values observed over Mexico City $\left(\left[\mathrm{CH}_{2} \mathrm{O}\right]_{\text {TDLAS meas }}=7793 \mathrm{pptv},\left[\mathrm{CH}_{2} \mathrm{O}\right]_{\text {model }}=7211 \mathrm{pptv}\right.$, and $[\mathrm{CO}]=600 \mathrm{ppbv}$ ). Fractional enhancements were calculated for each point and the age binned medians values are shown in Fig. 13. This approach allows one to plot all species on the same vertical axis, with all initial values starting at $\sim 1$ and decaying to 0 with time. The decay in $\mathrm{CO}$ here primarily reflects dilution as the plume ages, whereas the $\mathrm{CH}_{2} \mathrm{O}$ profiles reflect photochemical loss (reaction with $\mathrm{OH}$ and photolysis), dilution, and production as the plume ages. As can be seen, both TDLAS measured and modeled $\mathrm{CH}_{2} \mathrm{O}$ show net production relative to $\mathrm{CO}$, which persists as long as $\sim 1$ day downwind. In the case of box model $\mathrm{CH}_{2} \mathrm{O}$, this extra production can only arise from $\mathrm{CH}_{2} \mathrm{O}$ precursors at the time of measurement. Median $\mathrm{CH}_{2} \mathrm{O}$ production percentages from the model are: $\mathrm{CH}_{4}(46 \%)$, PAN and higher acetyl peroxy compounds (18\%), methanol $(8 \%)$, MHP $(7 \%)$ and ethene $(6 \%)$ for these air masses. All other precursor contributions are less than $2 \%$. The binned TDLAS $\mathrm{CH}_{2} \mathrm{O}$ observations, which are higher than both the modeled values and $\mathrm{CO}$ dilution, reflect additional production of $\mathrm{CH}_{2} \mathrm{O}$ in the aging outflow plume that is not accounted by the above precursors in the box model. This additional production lasts up to $\sim 2$ days, and most likely reflects additional $\mathrm{CH}_{2} \mathrm{O}$ production from unmeasured primary precursors, including multi-generation daughter species, as well as measured precursors that are not in

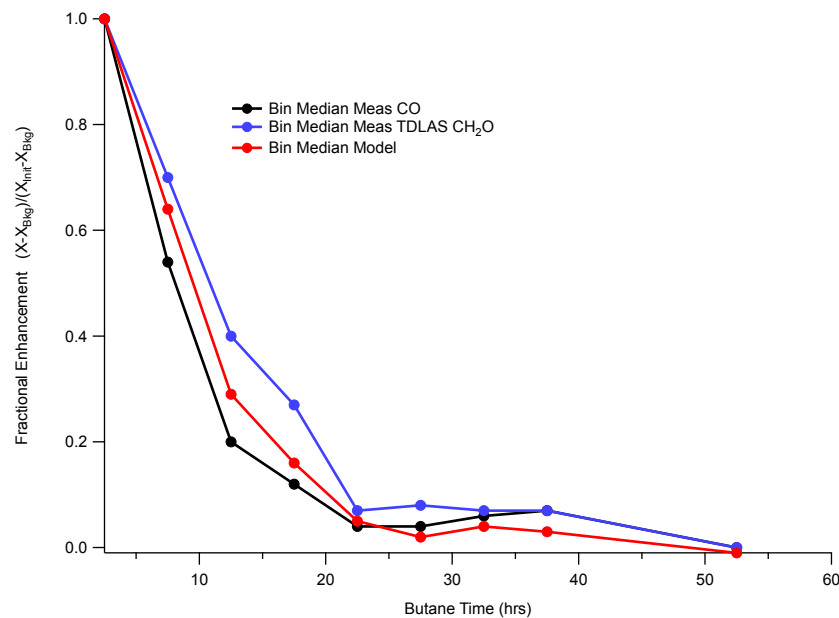

Fig. 13. Fractional enhancement for $\mathrm{CH}_{2} \mathrm{O}$ TDLAS measurements, box model values as well as $\mathrm{CO}$ observations as a function of the butane time employing a constant diurnally averaged $\mathrm{OH}$ concentration of $3 \times 10^{6}$ molecules $\mathrm{cm}^{-3}$ based upon Perring et al. (2010). The fractional enhancements were determined from Eq. (1) in the text.

steady-state with measured values from the DC-8. Biomass burning fire plumes, which have been noted in various Mexico City studies and could have an influence on such outflow plumes, do not play a significant role in the outflow events of Fig. 13. According to Kleinman et al. (2008), air masses have minimal forest fire influence for $\mathrm{CH}_{3} \mathrm{CN}$ (ppbv) $<0.2+0.4 \times 10_{*}^{-3}[\mathrm{CO}]$ (ppbv). For the present outflow events, $91 \%$ of the air masses have lower $\mathrm{CH}_{3} \mathrm{CN}$ mixing ratios than this.

To examine whether or not longer lived measured $\mathrm{CH}_{2} \mathrm{O}$ precursors could be responsible for the behavior shown in Fig. 13 during Mexico City outflow events, we employ the same Lagrangian-steady state analysis used in generating Fig. 11b. Here a Lagrangian Mexico City outflow plume (starting at noon) was simulated using input concentrations from the daytime mean measurements shown in Table 2 of Apel et al. (2010) along with $\mathrm{NO}_{\mathrm{x}}$ injections of $20 \mathrm{ppbv}$ and $\mathrm{O}_{3}$ held constant at $56 \mathrm{ppbv}$. The steady state box model sampled a continuously diluting Lagrangian plume at various times along the simulation. A dilution rate of $k_{\mathrm{d}}=$ $2.78 \times 10^{-5} \mathrm{~s}^{-1}$ (10 h CO lifetime) was estimated from the $\mathrm{CO}$ decay in Fig. 13 and this was used in the following relationship to arrive at diluted Lagrangian mixing ratios at every time step:

$X=X_{\mathrm{bkg}}+\left(X-X_{\mathrm{bkg}}\right) e^{-\left(\text {time } \cdot k_{\mathrm{d}}\right)}$

As in Eq. (1), $X_{\text {bkg }}$ is the background concentration observed at the longest photochemical time (photochemical lifetimes $>40 \mathrm{~h}$ ) over the Gulf and $X$ represents the concentration of species $X$ resulting from dilution and photochemistry at each time step. Figure 14 shows the ratio of the Lagrangian to steady state box model (red line with points) as 
a proxy of the measurement to steady-state box model relationship averaged over various outflow times. Here measurement/box model ratios in 5-h butane time bins are plotted as box and whiskers with median ratios highlighted by horizontal lines with blue points and fit using a 4-term polynomial (blue curve, $a+b x+c x^{2}+d x^{3}$ ). This plot shows enhanced production of $\mathrm{CH}_{2} \mathrm{O}$ with plume age, which reaches a maximum between $\sim 13$ and $28 \mathrm{~h}$. Here ratios and differences between measurements and the simple steady state box model are as high as 1.7 and 908 pptv, respectively. This plot indeed reveals additional production of $\mathrm{CH}_{2} \mathrm{O}$ that is not captured by the steady state model of about $20 \%$ for time periods as long as $40-50 \mathrm{~h}$ after injection. The species responsible for this include: higher aldehydes like acetaldehyde and higher peroxides, which are produced in large amounts at the beginning of the run and decay away much more slowly than $\mathrm{CH}_{2} \mathrm{O}$. Thus, the DSS modeling approach will underestimate the calculation of these species, which leads to the underestimation of $\mathrm{CH}_{2} \mathrm{O}$. It is interesting to note that this additional $20 \%$ of $\mathrm{CH}_{2} \mathrm{O}$ production is consistent with many of the geographic flight segment ratios shown in Fig. 9, which show averaged segment measurement/box model ratios around 1.2.

However, this additional production only accounts for about $1 / 3$ of the maximum additional $\mathrm{CH}_{2} \mathrm{O}$ suggested by the measurements around a photochemical age of $20 \mathrm{~h}$ and does not capture the shape of the measurement-box model discrepancy shown in Fig. 14. Even after accounting for such longer-lived precursors in the Lagrangian model approach, Fig. 14 reveals residual missing $\mathrm{CH}_{2} \mathrm{O}$ sources in the Mexico City outflow plume.

An analogous calculation was carried out using the online Leeds Master Chemical Mechanism (MCM version 3.1) to assess the effects of additional $\mathrm{CH}_{2} \mathrm{O}$ production from both measured hydrocarbons and unmeasured hydrocarbons with and without explicit chemistry involved in multi-generational production mechanisms. Details regarding the MCM can be found at http://mcm.leeds.ac.uk/MCM, and is further described by Jenkin et al. (1997, 2003), Saunders et al. (2003), and Bloss et al. (2005). In contrast to the limited suite of NMHCs available on the airborne platforms for box model calculations, the MCM utilizes a more comprehensive suite of observations from one of the fully instrumented Mexico City sampling sites at $T_{0}$. As indicated in Appendix Table A3, starting concentrations for the MCM runs were in most cases derived from 24-h median mixing ratios measured at $T_{0}$ by the Blake group at the University of California, Irvine. In some cases close-in measurements from the $\mathrm{C}-130$, the DC-8, or their averages were employed and these were scaled to $T_{0}$ values using similar reacting compounds. In all cases where measurements were employed, the "Model Input Designator" column of Appendix Table A3 lists a 1 or $\mathbf{2}$ designation. A 1 designates that the MCM was initialized using $T_{0}$ measurements of that species in the manner just described and that particular species was also explicitly measured on the NASA DC-8. Such species were used in constraining the

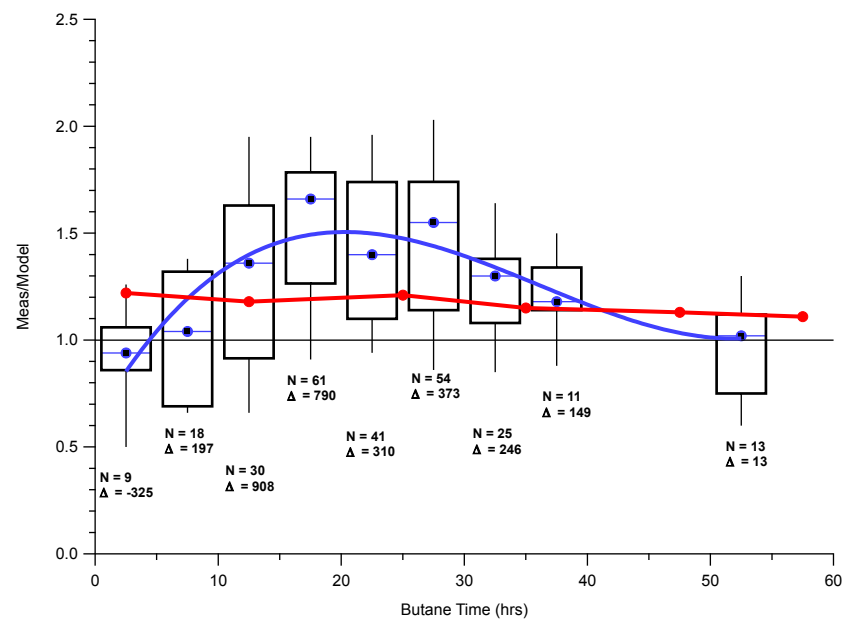

Fig. 14. Box and whisker plot for the TDLAS measurement/model ratio for Mexico City outflow events as a function of the butane time. The boxes denote the interquartile values, the horizontal lines with blue circles are the median ratios and the whisker represent 10 and 90 percentiles values. The blue solid profile is an empirical 4-term polynomial fit of the median Measurement/Box Model ratios to the butane time while the red line with points represents a proxy for this ratio based upon the ratio of Lagrangian-to-steady state predictions (see manuscript for details). The numbers below each whisker plot denote the number of comparisons in that bin (top number) and the median point-by-point measurement-model differences $(\Delta)$ in pptv are denoted by the lower numbers.

NASA box model. A 2 in this column indicates the same MCM source but no DC- 8 measurements were available. A 3 in this column designates that the MCM input mixing ratio was estimated by various methods. In some cases the estimation was from a fit of measured values versus carbon number for the same compound class as the unknown. In other cases estimations were based on the concentrations of similar reacting compounds. It should be noted that many of the secondary species designated by 2's and 3's, such as higher aldehydes and nitrates, are calculated by the NASA Langley box model based on the chemical production due to the observed parent NMHCs designated by $1 \mathrm{~s}$. So while these species are not constrained to the observed values, which reflect production from the full suite of NMHCs, their impact on $\mathrm{CH}_{2} \mathrm{O}$ formation is not neglected in the NASA box model. These designations were designed to elucidate the potentially important NMHC species that should be measured in future airborne campaigns when studying $\mathrm{CH}_{2} \mathrm{O}$ production.

The MCM explicitly follows the products from the degradation of 124 VOCs by $\mathrm{OH}, \mathrm{O}_{3}$, and $\mathrm{NO}_{3}$. Photolysis of relevant species (e.g. aldehydes) is also explicitly calculated. The mechanism produces a variety of free radical species (peroxy, oxy, and Criegee) that interact with each other and with the other oxidants. This leads to the production of many species, some of which have primary emissions (simple alcohols, aldehydes and ketones), but also those that are only formed in the atmosphere via multistep 
processes (multifunctional carbonyls, nitrates, peroxy nitrates, hydroperoxides, and carboxylic acids). While not all reactions of these species have been directly measured in the laboratory, the MCM makes use of available data to define rules to construct kinetic and mechanistic details for all species. In order to keep the mechanism to a manageable size, a few simplifications are made. Products from the attack of $\mathrm{OH}$ on many of the VOCs are ignored when the channel has a low probability of occurrence. Permutation reactions of a given $\mathrm{RO}_{2}$ radical are represented by a single parameterized reaction. Other minor processes are ignored if it is assessed that their contribution to the degradation of the VOC is relatively unimportant. As implemented, the mechanism has more than 13000 reactions and more than 4400 nonradical species. In addition, there are nearly 1000 peroxy radical species and more than 1000 alkoxy radical species. There are $290 \mathrm{CH}_{2} \mathrm{O}$ source reactions and 4 loss reactions. As can be seen by the input concentrations in Appendix Table $\mathrm{A} 3$, there is a large potential for significant $\mathrm{CH}_{2} \mathrm{O}$ production from secondary species that are unconstrained by aircraft observations. Among these are multifunctional species such as those generated from the attack of $\mathrm{OH}$ on alkenes (hydroxyl-carbonyls), hydroperoxides produced from $\mathrm{RO}_{2}$ reaction with $\mathrm{HO}_{2}$, and PAN-like species from substituted peroxy radical reactions with $\mathrm{NO}_{2}$. Estimation of the potential importance of oxidation of these species to produce $\mathrm{CH}_{2} \mathrm{O}$ is the reason for employing the MCM tool.

A dilution rate of $k_{\mathrm{d}}=2.5 \times 10^{-5} \mathrm{~s}^{-1}$ (a value similar to that used in the previous Lagrangian runs) was used in these calculations and this resulted in time dependent $\mathrm{CH}_{2} \mathrm{O}$ mixing ratios in 15-min time intervals for 4 different starting times between 00:00 and 18:00 h (00:00, 06:00, 12:00, 18:00). Rather than comparing MCM calculations directly with measured $\mathrm{CH}_{2} \mathrm{O}$ mixing ratios, which in addition to dilution, input values and comprehensive chemistry, depends upon accurate knowledge of the 3-D wind fields, we are more interested here in MCM comparisons using different input constraints and different scenarios involving the build up and further reaction of intermediate species. This was implemented by computing ratios involving four different MCM runs. In the $\operatorname{MCM}(\mathrm{a})$ run, all species listed in Table A3 (model input designators \#1, \#2, and \#3) were used to initialize the model and all species were allowed to build up and react. As this represents the most complete input and chemistry, all other runs were compared against $\operatorname{MCM}(a)$. In the $\operatorname{MCM}(\mathrm{b})$ run the model was initialized only using the values of species \#1 in Table A3 (species \#2 and \#3 were initialized to 0 ) but all species in the model were allowed to build up and react. In the MCM(c) run the model was again only initialized using the values of species \#1 in Table A 3 but species $\# 2$ and \#3 in this table were constrained to 0 throughout the model run (i.e. these species were initialized to 0 and not allowed to build up and react). In the MCM(ss) run, model run (a) was used to calculate all the instantaneous $\mathrm{CH}_{2} \mathrm{O}$ production $(P)$ and destruction terms $(D)$ and steady-state $\mathrm{CH}_{2} \mathrm{O}$ mixing ratios were determined from the ratio of $P / D$.

The results of the various MCM runs were averaged for daytime periods (when observations were made) over all starting times at each reaction time step to arrive at an average ratio at each 15 -min time step. Analogous to the measurement/box model ratios of Fig. 14, the time-dependent MCM data were fit to a 4-term polynomial for each run. For ease of reference, Fig. 15 reproduces the binned median (measurement/box model) polynomial fit as a function of processing time. This figure also displays the various MCM profiles. The red profile, which depicts the $\operatorname{MCM}(\mathrm{a}) / \mathrm{MCM}(\mathrm{ss})$ ratio, shows the non-steady-state contribution. The black profile, which represents the net sum of three contributions, the effects of non-steady-state, the effects of not initializing the model with species \#2 and \#3, and the effects of not allowing these additional species and their daughter products to build up and react, is the sum of the green and red profiles. The non-steady-state component was included in the black profile in order to directly compare with the (measured/box model) ratios, which contains this missing source. The black profile is thus most analogous to the blue (measurement/box model) profile. The gray profile shows the effects of incomplete model initialization, while the light blue profile was calculated by taking the difference of the green and gray profiles and depicts the impact of not allowing species \#2 and \#3 and hence their daughter products to build up and react.

While there are some differences between the (measured/box model) blue profile and the black MCM profile that encompasses the three $\mathrm{CH}_{2} \mathrm{O}$ contributions just discussed, the major features are remarkably similar. Both profiles display a sharp increase with processing time that peaks around $20-22 \mathrm{~h}$ and have peak ratios within $5 \%$ of one another. This suggests that the three contributions just discussed all play important roles when calculating $\mathrm{CH}_{2} \mathrm{O}$ mixing ratios in the Mexico City outflow. At $\sim 20 \mathrm{~h}$ of processing, Fig. 15 shows the following discrepancies relative to the full MCM(a) run: $\sim 19 \%$ assuming steady-state (red profile), $8 \%$ by initializing the model only using the DC- 8 observations (gray profile), and $\sim 18.5 \%$ by not allowing reactive intermediates to build up (i.e. the influence of multi-generation hydrocarbon oxidation processing as depicted by the light blue profile). Ignoring the effects of dilution in these calculations changes the results (using ratios from the various runs) by less than $4 \%$.

Inspection of the black profile in Fig. 15 reveals that its shape at short to intermediate processing times $(0$ to $\sim 30 \mathrm{~h})$ is primarily dictated by the non-steady-state component while at longer times the influence of multi-generation hydrocarbon oxidation processing and input constraints become more important. As can be seen these latter two influences do not properly capture the shape exhibited by the blue profile at times longer than $\sim 30 \mathrm{~h}$, and the reasons for this need to be further investigated. In fact, the shape of the non-steadystate red profile better matches the shape of the blue profile 


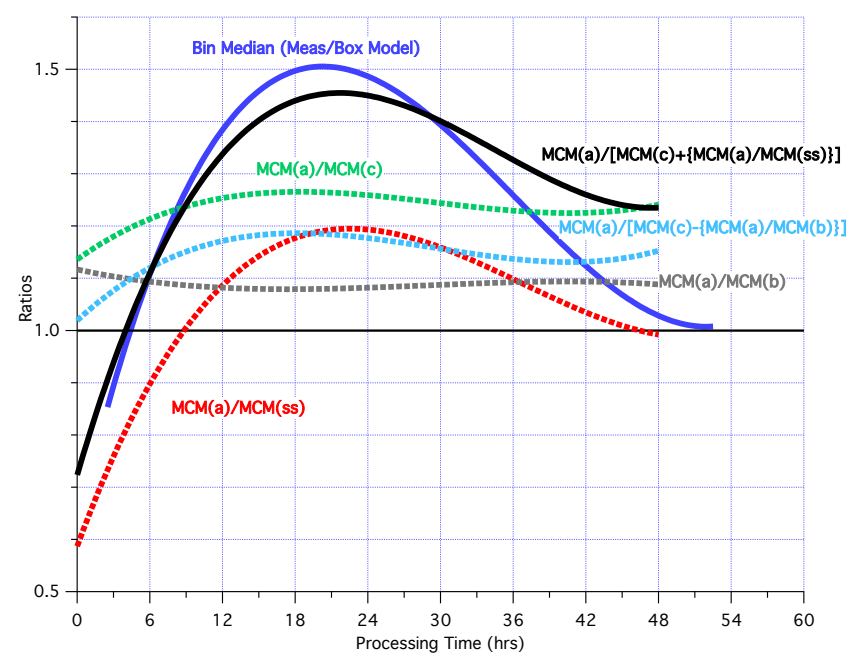

Fig. 15. 4-Term polynomial fits for various ratios as a function of processing time. The blue profile is the fit of the bin median (measurement/box model) ratio shown in Fig. 14 versus the butane time. The remaining profiles (black, green, red, light blue, and gray) are fits for the ratio of the Master Chemical Mechanism (MCM) using the complete chemistry of run a relative to MCM runs using various inputs versus processing time. In the $\operatorname{MCM}(a)$ run, all species in Table A3 were used to initialize the model and all species were allowed to build up and react. In the MCM(b) the model was initialized only using the values of species \#1 in Table A3 but all species in the model were allowed to build up and react. In MCM(c) run the model was again only initialized using the values of species \#1 in Table A3 but species \#2 and \#3 in this table were constrained to 0 throughout the model run (i.e. these species were not allowed to build up and react). The red MCM(a)/MCM(ss) profile was calculated using all the species in Table A3 by applying the steady-state assumption in the denominator. The black profile, which represents the net sum of three contributions, the effects of non-steady-state, the effects of not initializing the model with species \#2 and \#3, and the effects of not allowing these additional species and their daughter products to build up, is the sum of the green and red profiles. The gray profile shows the effects of incomplete model initialization, while the light blue profile was calculated by taking the difference of the green and gray profiles and depicts the impact of not allowing species \#2 \& \#3, and hence their daughter products to build up.

at such longer times. It is also interesting to note that the peak value of $\sim 19 \%$ in this profile is very similar to the additional $20 \%$ non-steady-state production of $\mathrm{CH}_{2} \mathrm{O}$ shown in Fig. 14. However, the two shapes are different.

The same MCM runs that produced the black profile in Fig. 15 were further examined to identify the major species responsible for producing the extra $\mathrm{CH}_{2} \mathrm{O}$ not accounted for in the less complete MCM runs. Seven major species were identified, and their dependence on transport time is shown in Fig. 16. This figure only includes the reactive intermediates that produce $\mathrm{CH}_{2} \mathrm{O}$ and not the starting parent species for which the MCM was initialized. As can be seen, the 7 major missing $\mathrm{CH}_{2} \mathrm{O}$ precursors are multiply-substituted second-

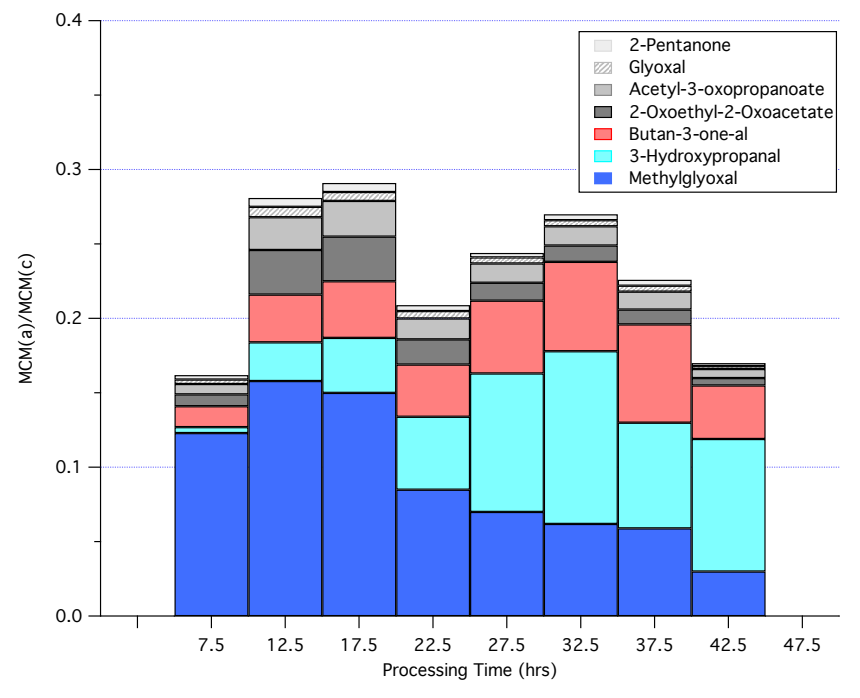

Fig. 16. The 7 major species responsible for producing the $\mathrm{CH}_{2} \mathrm{O}$ that is not accounted for when constraining species \#2 \& \#3 in Table A3 to 0 throughout the model run (green profile of Fig. 15). These species are multiply-substituted second-and highergenerational products of species for which the MCM was initialized.

and higher-generational products, with the largest contribution in many cases from methylglyoxal. In the 15 to $20 \mathrm{~h}$ bin, $\sim 51 \%$ of the missing $\mathrm{CH}_{2} \mathrm{O}$ source in the $\mathrm{MCM}(\mathrm{a}) / \mathrm{MCM}(\mathrm{c})$ ratio originates from methylglyoxal.

The above results imply that inaccuracies in model calculations for secondary species such as aldehydes like methylglyoxal have the potential to significantly contribute to inaccuracies in calculations of $\mathrm{CH}_{2} \mathrm{O}$ in a complex mixture of hydrocarbons such as that found in the outflow of Mexico City. Accurate observations of these higher aldehydes to verify model predictions of these species would be a valuable addition to the typical suite of measurements available for airborne campaigns. Although we have shown the importance of incorporating explicit chemical mechanisms that involve multi-generation hydrocarbon processing and a comprehensive suite of measurements in such complex regimes, results of this study do not directly test differences between explicit and lumped mechanisms, such as employed in the MCM and box model calculations, respectively. Such headto-head comparisons will be the topic of another paper.

In contrast to the behavior above, additional sources of $\mathrm{OH}$ above pristine forested regions dominated by isoprene emissions in the Amazon (Lelieveld, et al., 2008 and references therein) boundary layer and over a South-East Asian tropical rainforest (Stone et al., 2011) have been reported. Traditional isoprene models for these regions significantly underestimate observations of $\mathrm{OH}$ and this has led Peeters et al. (2009), Lelieveld et al. (2008), Stone et al. (2011) and Crounse et al. (2011) among others to propose new $\mathrm{HO}_{\mathrm{x}}$ radical regeneration mechanisms during isoprene oxidation under low NO 
mixing ratios $(\leq 20 \mathrm{pptv})$. To investigate the importance of such chemistry in the present Mexico City outflow plumes where NO mixing ratios were factors of 3.5 to 10 higher, we included these $\mathrm{HO}_{\mathrm{x}}$ recycling mechanisms in an additional MCM run. Negligible additional $\mathrm{CH}_{2} \mathrm{O}$ was produced from these reactions.

\section{Summary and conclusions}

A detailed investigation of $\mathrm{CH}_{2} \mathrm{O}$ measurements acquired by tunable diode laser absorption spectroscopy and steady state box model calculations using data from the INTEXB/MILAGRO campaign in 2006 reveals the presence of additional factors that must be taken into account when carrying out such comparisons in the boundary layer and/or within $\sim 2$ days of very large emission sources such as those from megacities. Detailed comparisons indicate large discrepancies, primarily in the $0-2 \mathrm{~km}$ (radar altitude) boundary layer, that can neither be explained by: timing errors between measurements and model inputs; combined measurement and box model uncertainty limits; errors in kinetic rate constants and branching ratios; or systematic measurement interferences.

Close to large emission sources of fast reacting alkenes like ethene, measurement-steady-state box model $\mathrm{CH}_{2} \mathrm{O}$ comparisons need to take into account processing times in order for such comparisons to make sense. In this study using processing times based on the ratio of 2-butyl nitrate to butane employing measured $\mathrm{OH}$ mixing ratios, measurement/steady-state box model ratios are in reasonable agreement out to processing times of $\sim 4$ to $6 \mathrm{~h}$ only when the $\mathrm{CH}_{2} \mathrm{O}$ temporal dependence is taken into account. Depending upon the exact processing time and lifetimes of $\mathrm{CH}_{2} \mathrm{O}$ and the alkene, one can expect model overestimations (factor of $\sim 2$ ), underestimations (factor of $\sim 1.6$ ), or exact agreement with measurements.

This analysis further shows that at longer processing times during Mexico City outflow events, binned median measurement/steady state box model ratios indicate influences from non-steady-state conditions. The ratios show discrepancies as large as 1.7 and 908 pptv for the binned ratios and differences, respectively, for processing times of 10-30 h. Approximately one-third of these discrepancies can be accounted for using an analysis where Lagrangian outflow model calculations, employing typical VOC mixing ratios observed over Mexico City, are sampled by the steady-state box model. Lagrangian/box model ratios up to 1.2 were observed for up to $40-50 \mathrm{~h}$ in this analysis. Aldehydes like acetaldehyde and higher peroxides, which are produced in large amounts at the beginning of the run and decay away much more slowly than $\mathrm{CH}_{2} \mathrm{O}$, are responsible for this $\sim 20 \%$ non-steady state discrepancy. Such a value is consistent with discrepancies observed for many of the geographically averaged flight segments over the Gulf in the boundary layer. Further analysis using the Leeds Master Chemical Mechanism to simulate the full suite of chemical reactions using both measured NMHCs and an estimate of a mix of unmeasured hydrocarbons during this study indicates that unmeasured VOCs, including those from multi-generation oxidation processes, have the potential to influence $\mathrm{CH}_{2} \mathrm{O}$ concentrations for up to two days of processing and this can account for the majority of the measurement-modeling discrepancy observed during Mexico City outflow events. The maximum effect occurs at processing times between 18 and $22 \mathrm{~h}$, with the largest contribution coming from methylglyoxal, which was not measured on the DC-8 during this campaign.

Although simplified steady-state box model calculations accurately simulate $\mathrm{CH}_{2} \mathrm{O}$ observations in many cases, we have presented in this study a possible scenario by which multi-generation $\mathrm{CH}_{2} \mathrm{O}$ production can explain observed and calculated $\mathrm{CH}_{2} \mathrm{O}$ mixing ratios outside immediate emission regions. This, together with the other aforementioned steady-state issues, further suggest that more a comprehensive chemical mechanism involving explicit chemistry as well as a more comprehensive suite of input species may be required to accurately simulate $\mathrm{CH}_{2} \mathrm{O}$ observations 1 to 2 days old where the input air has been influenced by very large hydrocarbon emission sources, such as those from megacities. The role of $\mathrm{OH}$ recycling in this regime was found to be negligible. Although this study shows the importance of erroneous and/or incomplete chemistry due to higher generation reaction intermediates as a potential additional source of model systematic uncertainty, this more difficult source to quantify was not included in our present systematic analysis. Although it is hard to state with certainty if these causes were also responsible for the boundary layer discrepancies we have observed in certain locations in other studies and observed in this study in the boundary layer over the Gulf of Mexico, Mexico, and over parts of the United States, these must be strongly considered as likely possibilities. The various modeling runs highlight the potential importance of various dicarbonyls and hydroxy-carbonyls in generating $\mathrm{CH}_{2} \mathrm{O}$ about two days downwind of large emission sources and that future airborne $\mathrm{CH}_{2} \mathrm{O}$ measurement-box model comparisons should include measurements of these species, particularly methylglyoxal and 3-hyroxypropanal. Efforts are currently underway to identify the starting parent species for the various reactive intermediates, and this will be the subject of a future publication. In addition, such a future paper will provide a more definitive direct comparison of explicit chemical mechanisms relative to lumped schemes.

The results of this study must also be considered when apportioning $\mathrm{CH}_{2} \mathrm{O}$ into primary and secondary production sources for effective ozone control strategies, as exemplified by Garcia et al. (2006) and Rappenglück et al. (2010 and reference therein). The additional significant 1 to 2 day old $\mathrm{CH}_{2} \mathrm{O}$ production we hypothesize here could also be responsible for a large part of the "residual unaccounted $\mathrm{CH}_{2} \mathrm{O}$ " deduced from such studies, particularly if the outflow 
re-circulates over the source region. In these studies, such $\mathrm{CH}_{2} \mathrm{O}$ represents the amount that could neither be assigned to primary or secondary production sources. Over Mexico City in the spring of 2003, Garcia et al. (2006) deduced that up to $21 \%$ of the observed $\mathrm{CH}_{2} \mathrm{O}$ (or 2 ppbv) falls into this category, and pointed out that such "unaccounted" $\mathrm{CH}_{2} \mathrm{O}$ tends to correlate with higher temperatures and higher ozone in the metropolitan area. The results of the present study add independent support to this conclusion, and indicate that such "residual $\mathrm{CH}_{2} \mathrm{O}$ " indeed falls within the secondary production category.

\section{Appendix A}

\section{Overview of measurement and box model approaches and uncertainty analysis}

A detailed discussion of the TDLAS employed in this work can be found in Fried et al. (2008a, b) and only a very brief overview is presented here. The present instrument is essentially the same as that employed during the INTEX-NA study but with a number of enhancements to the optical system to improve mechanical stability, and hence, measurement performance. As previously discussed, $\mathrm{CH}_{2} \mathrm{O}$ is measured via absorption spectroscopy using a liquid nitrogen cooled tunable lead-salt diode laser to selectively probe a moderately strong and isolated $\mathrm{CH}_{2} \mathrm{O}$ absorption feature at $3.53-\mu \mathrm{m}\left(2831.6417 \mathrm{~cm}^{-1}\right)$ employing a multipass Herriott sampling cell (optical pathlength of 100-m). Ambient measurements were acquired in 1-s increments over time periods ranging from 30 to $120 \mathrm{~s}$, and this was followed by $15 \mathrm{~s}$ of background zero air acquisition, obtained by overflowing the inlet with zero air using a commercial Aadco ${ }^{\mathrm{TM}}$ zero air generation system to remove $\mathrm{CH}_{2} \mathrm{O}$ from the sample stream. During most of the INTEX-B first phase, the ambient mixing ratios were sufficiently high compared to backgrounds that ambient acquisition periods as long as 60 to $120 \mathrm{~s}$ were possible before the acquisition of a new background was required. During the second phase over the Pacific, the lower ambient $\mathrm{CH}_{2} \mathrm{O}$ levels required more frequent background acquisitions every $30 \mathrm{~s}$. In all cases, the time-weighted average of the background spectra surrounding each ambient period was subtracted point-by-point from each ambient $1 \mathrm{~s}$ spectrum, and the resultant spectra were fit to a background-subtracted reference spectrum. The latter was obtained by introducing a high concentration $(\sim 8 \mathrm{ppbv}) \mathrm{CH}_{2} \mathrm{O}$ calibration mixture from a permeation system in zero air approximately every hour. Further details regarding these calibrations, the inlet, typical operating conditions, data handling and fitting, zero air background subtraction, and assessments of measurement accuracy and limits of detection, can be found in Fried et al. (2008a) and references therein.

Enhanced measurement performance was achieved in this study by mechanical stabilizing three critical system optical
Table A1. DC-8 (TDLAS) and ground-based (Hantzsch) comparisons of ambient $\mathrm{CH}_{2} \mathrm{O}$ over Mexico City. The distance is the aircraft distance to the site and the altitude is the height above ground from the aircraft radar. The mixing ratios are in ppbv.

\begin{tabular}{llrrrr}
\hline $\begin{array}{l}\text { Ground } \\
\text { Site }\end{array}$ & $\begin{array}{l}\text { Date/Time } \\
(\text { GMT })\end{array}$ & $\begin{array}{r}\text { Distance } \\
(\mathrm{km})\end{array}$ & $\begin{array}{r}\text { Altitude } \\
(\mathrm{km})\end{array}$ & $\begin{array}{r}{\left[\mathrm{CH}_{2} \mathrm{O}\right]} \\
\text { Hantzsch }\end{array}$ & $\begin{array}{r}{\left[\mathrm{CH}_{2} \mathrm{O}\right]} \\
\text { TDLAS }\end{array}$ \\
\hline Tenago & $3 / 12 / 0622: 28: 01$ & 4 & 0.32 & 8.070 & 7.752 \\
$T_{1}$ & $3 / 11 / 0620: 22: 34$ & 6.2 & 0.28 & 5.440 & 5.189 \\
\hline
\end{tabular}

Table A2a. C-130 (DFG) and ground-based (Hantzsch) comparisons of ambient $\mathrm{CH}_{2} \mathrm{O}$ over Mexico City. The distance is the aircraft distance to the site and the altitude is the height above ground from the aircraft radar. The mixing ratios are in ppbv.

\begin{tabular}{llrrrr}
\hline $\begin{array}{l}\text { Ground } \\
\text { Site }\end{array}$ & $\begin{array}{l}\text { Date/Time } \\
(\mathrm{GMT})\end{array}$ & $\begin{array}{r}\text { Distance } \\
(\mathrm{km})\end{array}$ & $\begin{array}{r}\text { Altitude } \\
(\mathrm{km})\end{array}$ & $\begin{array}{r}{\left[\mathrm{CH}_{2} \mathrm{O}\right]} \\
\text { Hantzsch }\end{array}$ & $\begin{array}{r}{\left[\mathrm{CH}_{2} \mathrm{O}\right]} \\
\text { DFG }\end{array}$ \\
\hline$T_{0}$ & $3 / 22 / 0620: 18: 00$ & 0.8 & 0.59 & 11.270 & 11.159 \\
$T_{1}$ & $3 / 22 / 0620: 27: 00$ & 3.1 & 1.04 & 6.630 & 6.730 \\
$T_{1}$ & $3 / 22 / 0620: 39: 00$ & 3.9 & 1.66 & 7.030 & 6.747 \\
$T_{1}$ & $3 / 22 / 0620: 40: 00$ & 3.6 & 1.72 & 7.070 & 6.360 \\
\hline
\end{tabular}

components. The first involved the Herriott cell. Roller et al. (2006) discussed a clamping arrangement on the Herriott cell to eliminate changes in mirror pitch and separation during aircraft maneuvers. We further improved on this design. We also mechanically stabilized the first off-axis parabolic (OAP) mirror mount used in collecting and collimating the diode laser radiation. This was accomplished using a clamp to provide continuous downward pressure to the OAP mount and translation stages. Prior to this, even small vertical aircraft accelerations moved the optical beam, and given the large magnification of this first mirror $(\sim 75)$, such small movements resulted in large beam movements into and out of the Herriott cell, significantly degrading system performance. The cell input/output mirror stage was also mechanically stabilized in the same fashion. All three actions led to improved performance.

As discussed by Fried et al. (2008a), the $2831.6 \mathrm{~cm}^{-1}$ $\mathrm{CH}_{2} \mathrm{O}$ line is free from all known spectroscopic interferences with the exception of methanol. Extensive laboratory tests indicate that with proper choice of fitting windows, this interference can be reduced to $0.3 \%$ in the present TDLAS system (i.e. an error in the retrieved $\mathrm{CH}_{2} \mathrm{O}$ mixing ratio of $+0.3 \%$ times the ambient methanol mixing ratio). The results of the present study, however, were not corrected for this small interference since ambient measurements of methanol on the DC-8 were only available from one of the airborne instruments (the NASA Ames PANIK instrument) less than $50 \%$ of the time when $\mathrm{CH}_{2} \mathrm{O}$ measurements and box model values were compared. This small positive measurement bias only has a minimal effect on the boundary layer results; when methanol data were available 
Table A2b. C-130 (DFG) and ground-based DOAS comparisons of ambient $\mathrm{CH}_{2} \mathrm{O}$ over Mexico City. The distance is the aircraft distance to the site and the altitude is the height above ground from the aircraft radar. The mixing ratios are in ppbv. The assumed boundary layer height (BL) in $\mathrm{km}$ is also indicated as well as the DOAS measurement time. The DOAS $\mathrm{CH}_{2} \mathrm{O}$ was normalized by the DOAS/C-130 measurements of $\mathrm{NO}_{2}$ to account for errors in the BL determination.

\begin{tabular}{llrrrrrr}
\hline $\begin{array}{l}\text { Ground } \\
\text { Site }\end{array}$ & $\begin{array}{l}\text { Date/Time } \\
\text { (GMT) Aircraft }\end{array}$ & $\begin{array}{r}\text { Time } \\
(\text { GMT DOAS }\end{array}$ & $\begin{array}{r}\text { Distance } \\
(\mathrm{km})\end{array}$ & $\begin{array}{r}\text { Altitude } \\
(\mathrm{km})\end{array}$ & $\begin{array}{r}{\left[\mathrm{CH}_{2} \mathrm{O}\right]} \\
\text { DOAS }\end{array}$ & $\begin{array}{r}{\left[\mathrm{CH}_{2} \mathrm{O}\right]} \\
\text { DFG }\end{array}$ & $\begin{array}{r}\mathrm{BL} \\
(\mathrm{km})\end{array}$ \\
\hline$T_{0}$ & $3 / 22 / 0620: 18: 00$ & $19: 46: 05$ & 0.8 & 0.59 & 12.023 & 11.159 & 1.63 \\
$T_{0}$ & $3 / 29 / 0620: 25: 00$ & $19: 42: 47$ & 0.4 & 0.57 & 10.926 & 10.669 & 1.50 \\
$T_{2}$ & $3 / 29 / 0619: 14: 00$ & $20: 54: 46$ & 2.2 & 0.64 & 2.323 & 2.095 & 1.06 \\
\hline
\end{tabular}

for correction, the median $\mathrm{CH}_{2} \mathrm{O}$ (measurement-model) difference only changed by 47 pptv for all boundary layer comparisons during the 1 st phase. This is at least an order of magnitude smaller than observed differences.

Box model simulations were carried out employing the NASA Langley time dependent photochemical box model (Crawford et al., 1999; Olson et al., 2001, 2006) with rate constants generally those recommended by Sander et al. (2006) and Atkinson et al. (2006). The parameterization for near-IR photolysis of $\mathrm{HNO}_{4}$ as described in Roehl et al. (2002) is included. NMHC chemistry is originally based on the lumped scheme in Lurmann et al. (1986), with appropriate adjustments to chemistry as discussed in the appendix of Crawford et al. (1999). As discussed in Fried et al. (2008a), the model calculates for each set of measurements the associated self-consistent diurnal profile of radical and other computed species determined from the constraint of long-lived precursors to measured concentrations. Computed radical concentrations at the same point in time as the measurement are then used as the instantaneous model results. The hydrocarbon (HC) sampling time base, which represents the time duration in filling each hydrocarbon canister, was used in these calculations, as discussed previously. The average canister fill duration was $70 \mathrm{~s}$. The minimum set of input constraints includes observations of $\mathrm{O}_{3}, \mathrm{CO}, \mathrm{NO}$, nonmethane hydrocarbons (NMHCs), acetone, MEK, methanol, ethanol, temperature, $\mathrm{H}_{2} \mathrm{O}$ (dew/frost point), pressure, photolysis frequencies, and when available, measurements of $\mathrm{H}_{2} \mathrm{O}_{2}, \mathrm{HNO}_{3}$, and PAN. Ketones, alcohols, and NMHCs are filled by interpolation or scaling to $\mathrm{CO}$ when measurements are unavailable. A further restricted dataset was derived where measurements of MHP were available to constrain the model, where the $\mathrm{CH}_{2} \mathrm{O}$ measurements comprised at least $50 \%$ of the $\mathrm{HC}$ time base, and where the measurements were uniformly distributed over this time base. Depositional loss of $\mathrm{CH}_{2} \mathrm{O}$ and other soluble species was invoked below $2 \mathrm{~km}$ at a constant value of $1.0 \times 10^{-5} \mathrm{~s}^{-1}\left(1.2 \mathrm{~cm} \mathrm{~s}^{-1}\right.$ deposition velocity).

The limits of detection (LOD, $2 \sigma$ level) for the 1-min TDLAS results discussed here were independently determined for each flight based upon the median replication precision of 1-s ambient measurements over 30-s to 1-min time inter- vals. Laboratory tests have shown that the instrument precision generally improved by the square-root of the averaging time up to averaging periods of 30 to 60 -s. Equivalent 1-min precisions were determined from the 1-s precisions by dividing these results by the square-root of 30 in all cases (even for 60 -s of averaging, just to be conservative). Since ambient variability can contribute to the signal variability, these LOD estimates are conservative upper limits. Using these procedures we arrive at 1-min $(2 \sigma)$ measurement LODs ranging between $39 \mathrm{pptv}$ to $59 \mathrm{pptv}$ for the entire mission with a median value of $47 \mathrm{pptv}$ for all flights combined. These values were further confirmed on a number of occasions from the replicate precision of 1-min ambient measurements carried out over at least 5-min when the ambient $\mathrm{CH}_{2} \mathrm{O}$ mixing ratios were low and stable. A total systematic error ( $2 \sigma$ level) of $13 \%$ was estimated from the quadrature addition of various individual uncertainties involving flow and flow dilution uncertainties, and uncertainties in the $\mathrm{CH}_{2} \mathrm{O}$ permeation rate and calibration factors over the course of the mission.

The uncertainty in box model predictions of $\mathrm{CH}_{2} \mathrm{O}$ and other radicals include a component due to uncertainties in the measurement of constrained species (model constraint uncertainty), and a component due to uncertainties in kinetic and photolytic rates (model kinetic uncertainty). This latter term also includes uncertainties in the molecular parameters used in calculating these photolytic rates. Uncertainties in the actinic flux measurements, which are one component of the photolytic rate determinations, ranged between 4 and $5.8 \%$, and these are included in the model constraint uncertainty. Although this study shows the importance of erroneous and/or incomplete chemistry due to higher generation reaction intermediates as a potential additional source of model systematic uncertainty, this more difficult source to quantify was not included in our present analysis. The model constraint uncertainty was determined for every modeled point on the hydrocarbon time base using a sensitivity approach similar to Frost et al. (2002). The box model was run 11 times for every data point; each time one of the 11 constraints considered was increased by its given $1 \sigma$ measurement uncertainty. The considered constraints include $\mathrm{O}_{3}$, $\mathrm{CO}, \mathrm{NO}$, acetone, alcohols, ethene, higher alkenes, alkanes, isoprene, and MHP. The absolute value of the relative change 
Table A3. Initial species mixing ratios (pptv unless otherwise indicated) used in MCM runs. The "Source" column indicates how these mixing ratios were determined. In the "Model Input Designator" column a 1 indicates that measurements were used and that the NASA Langley Box Model explicitly incorporates DC-8 measurements of that species as an input. MCM measurements were typically from 24$\mathrm{h}$ median University of California Irvine (UCI) ground-based measurements at $T_{0}$ (see Apel et al., 2010) where available, or from aircraft measurements (C-130, DC-8 or their average). A 2 indicates the same MCM measurement source but the NASA Box Model did not explicitly incorporate that species as an input, and a $\mathbf{3}$ indicates an unmeasured species in both models whose mixing ratio was estimated.

\begin{tabular}{|c|c|c|c|c|}
\hline Class & $\begin{array}{l}\text { Species/ } \\
\text { Parameter }\end{array}$ & $\begin{array}{l}\text { Mixing } \\
\text { Ratio }\end{array}$ & $\begin{array}{l}\text { Model Input } \\
\text { Designator }\end{array}$ & Source \\
\hline \multirow[t]{5}{*}{ Major } & Methane & $2,800 \mathrm{ppbv}$ & 1 & T0-Blake ${ }^{a}$ \\
\hline & Water & $6670 \mathrm{ppmv}$ & 1 & Outflow average $^{c}$ \\
\hline & Carbon monoxide & $1600 \mathrm{ppbv}$ & 1 & T0-Blake \\
\hline & Ozone & $5 \mathrm{ppbv}$ & 1 & T0-Kolb ${ }^{b}$ \\
\hline & Hydrogen & $550 \mathrm{ppbv}$ & & Typical value \\
\hline \multirow[t]{21}{*}{ NMHC-Alkanes } & Ethane & 10000 & 1 & T0-Blake \\
\hline & Propane & 60000 & 1 & T0-Blake \\
\hline & i-Butane & 12000 & 1 & T0-Blake \\
\hline & n-Butane & 31000 & 1 & T0-Blake \\
\hline & i-Pentane & 8000 & 1 & T0-Blake \\
\hline & neo-Pentane & 10 & 3 & Small value estimate \\
\hline & n-Pentane & 5600 & 1 & T0-Blake \\
\hline & 2,2-Dimethylbutane & 730 & 2 & T0-Blake \\
\hline & 2,3-Dimethylbutane & 3700 & 2 & T0-Blake \\
\hline & 2-Methylpentane & 3400 & 1 & T0-Blake \\
\hline & 3-Methylpentane & 2500 & 1 & T0-Blake \\
\hline & Cyclohexane & 400 & 2 & T0-Apel \\
\hline & n-Hexane & 3800 & 1 & T0-Blake \\
\hline & 2-Methylhexane & 700 & 3 & fit of Alkanes vs $\# C^{f}$ \\
\hline & 3-Methylhexane & 700 & 3 & fit of Alkanes vs \#C ${ }^{f}$ \\
\hline & n-Heptane & 760 & 1 & T0-Blake \\
\hline & n-Octane & 270 & 2 & T0-Blake \\
\hline & n-Nonane & 190 & 2 & T0-Blake \\
\hline & n-Decane (ND) & 290 & 2 & T0-Blake \\
\hline & Undecane (UD) & 100 & 3 & fit (UD/ND)*ND (@T0) ${ }^{\mathrm{f}}$ \\
\hline & Dodecane (DD) & 40 & 3 & fit (DD/ND)*ND $(@ \mathrm{~T} 0)^{\mathrm{f}}$ \\
\hline \multirow[t]{18}{*}{ Alkenes } & Ethene & 11000 & 1 & T0-Blake \\
\hline & Propene & 3000 & 1 & T0-Blake \\
\hline & 1,3-Butadiene & 230 & 1 & T0-Blake \\
\hline & 1-Butene & 1100 & 1 & T0-Blake \\
\hline & i-Butene & 500 & 2 & T0-Blake \\
\hline & cis-2-Butene & 400 & 1 & T0-Blake \\
\hline & trans-2-Butene & 420 & 1 & T0-Blake \\
\hline & 1-Pentene & 240 & 2 & T0-Blake \\
\hline & 2-Methyl-1-Butene & 1 & 3 & Estimate \\
\hline & 2-Methyl-2-Butene & 700 & 2 & T0-Apel \\
\hline & 3-Methyl-1-Butene & 120 & 2 & T0-Apel ${ }^{\mathrm{e}}$ \\
\hline & cis-2-Pentene & 210 & 2 & T0-Blake \\
\hline & Isoprene & 180 & 1 & T0-Blake \\
\hline & trans-2-Pentene & 410 & 2 & T0-Blake \\
\hline & 1-Hexene & 200 & 3 & fit of alkenes vs \#C ${ }^{f}$ \\
\hline & 2,3-Dimethylbut-2-ene & 200 & 3 & fit of alkenes vs. $\# C^{f}$ \\
\hline & cis-2-Hexene & 200 & 3 & fit of alkenes vs \#C \\
\hline & trans-2-Hexene & 200 & 3 & fit of alkenes vs \#C $C^{f}$ \\
\hline Alkynes & Ethyne & 12000 & 1 & T0-Blake \\
\hline
\end{tabular}


Table A3. Continued.

\begin{tabular}{|c|c|c|c|c|}
\hline Class & $\begin{array}{l}\text { Species/ } \\
\text { Parameter }\end{array}$ & $\begin{array}{l}\text { Mixing } \\
\text { Ratio }\end{array}$ & $\begin{array}{l}\text { Model Input } \\
\text { Designator }\end{array}$ & Source \\
\hline \multirow[t]{17}{*}{ Aromatics } & Benzene & 1700 & 1 & T0-Blake \\
\hline & Toluene & 16000 & 1 & T0-Blake \\
\hline & Ethylbenzene & 1400 & 1 & T0-Blake \\
\hline & m-Xylene & 1200 & 1 & T0-Blake \\
\hline & o-Xylene & 600 & 1 & T0-Blake \\
\hline & p-Xylene & 430 & 1 & T0-Blake \\
\hline & Styrene & 40 & 3 & Small like 1-butanol \\
\hline & 1,2,3-Trimethylbenzene & 350 & 3 & Estimate \\
\hline & 1,2,4-Trimethylbenzene & 1500 & 1 & T0-Blake \\
\hline & 1,3,5-Trimethylbenzene & 230 & 1 & T0-Blake \\
\hline & 2-Ethyltoluene & 140 & 1 & T0-Blake \\
\hline & 3-Ethyltoluene & 370 & 1 & T0-Blake \\
\hline & 4-Ethyltoluene & 200 & 1 & T0-Blake \\
\hline & i-Propylbenzene & 60 & 1 & T0-Blake \\
\hline & n-Propylbenzene & 190 & 1 & T0-Blake \\
\hline & 3,5-Dimethyl-ethylbenzene & 40 & 3 & Small like 1-butanol \\
\hline & 3,5-Diethyltoluene & 40 & 3 & Small like 1-butanol \\
\hline \multirow[t]{3}{*}{ Other Species } & Sulfur dioxide & 2200 & 1 & T0-Kolb \\
\hline & Hydrogen peroxide & 1000 & 1 & MCMA average $^{\mathrm{d}}$ \\
\hline & Methylhydroperoxide & 400 & 1 & MCMA average $^{d}$ \\
\hline \multirow[t]{4}{*}{ Odd Nitrogen } & $\mathrm{NO}_{\mathrm{X}}$ & 86000 & 1 & T0-Kolb \\
\hline & Nitrous Acid & 1450 & 1 & T0-Kolb \\
\hline & PAN & 18000 & 1 & $\mathrm{~A} / \mathrm{C}\left(\mathrm{PAN} / \mathrm{NO}_{\mathrm{x}}\right) * \mathrm{NO}_{\mathrm{x}}(@ \mathrm{~T} 0)$ \\
\hline & PPN & 2400 & 3 & A/C(PPN/PAN)*PAN (est@ T0) \\
\hline \multirow[t]{12}{*}{ Aldehydes } & Formaldehyde & 5000 & 1 & T0-Kolb \\
\hline & Acetaldehyde & 6000 & 1 & T0-Kolb \\
\hline & Glyoxal & 200 & 2 & T0-Kolb \\
\hline & Glyoxylic acid & 50 & 3 & Estimate \\
\hline & Methylglyoxal & 100 & 3 & Estimate \\
\hline & Propanal (Prpn) & 2850 & 1 & A/C (Prpn/MeOH)* MeOH (@ @0) \\
\hline & Biacetyl & 100 & 3 & Estimate \\
\hline & Butanal (Btnl) & 850 & 3 & A/C (Btnl/MeOH)* MeOH (@T0) \\
\hline & Methylpropanal & 40 & 3 & Ratio to Butanal \\
\hline & Pentanal (Ptnl) & 5 & 3 & A/C (Ptnl/DIEK)* DIEK (@T0est) \\
\hline & Hexanal (Hxnl) & 200 & 3 & A/C (Hxnl/Btnl)*Btnl (@T0 est) \\
\hline & Benzaldehyde & 40 & 3 & Same as methylpropanal \\
\hline \multirow[t]{10}{*}{ Ketones } & Acetone (Actn) & 8400 & 1 & T0-Kolb \\
\hline & MEK & 1300 & 1 & A/C (MEK/Actn)*Actn (@ T0) \\
\hline & 2-Pentanone (MRPK) & 800 & 3 & A/C (MPRK/MEK)*MEK (@T0) \\
\hline & 3-Pentanone (DIEK) & 40 & 3 & A/C(DIEK/MPRK)*MPRK(@T0) \\
\hline & Methyl isopropyl ketone (MIPK) & 600 & 3 & Estimate \\
\hline & 2-Hexanone (2Hxn) & 10 & 3 & A/C (2Hxn/DIEK)* DIEK(@ @ 0 est) \\
\hline & 3-Hexanone & 10 & 3 & Same as 2-hexanone \\
\hline & Cyclohexanone & 40 & 3 & Same as methylpropanal \\
\hline & 4-methyl-2-pentanone (MIBK) & 40 & 3 & Same as methylpropanal \\
\hline & 3,3-dimethyl-2-butanone (MTBK) & 40 & 3 & Same as methylpropanal \\
\hline
\end{tabular}


Table A3. Continued.

\begin{tabular}{|c|c|c|c|c|}
\hline Class & $\begin{array}{l}\text { Species/ } \\
\text { Parameter }\end{array}$ & $\begin{array}{l}\text { Mixing } \\
\text { Ratio }\end{array}$ & $\begin{array}{l}\text { Model Input } \\
\text { Designator }\end{array}$ & Source \\
\hline \multirow[t]{9}{*}{ Alcohols } & Methanol (MeOH) & 28500 & 1 & T0-Kolb \\
\hline & Ethanol (EtOH) & 4000 & 1 & A/C (EtOH/MeOH)*MeOH (@ @ \\
\hline & 1-Propanol & 300 & 3 & Estimate: $0.01 * \mathrm{MeOH}$ \\
\hline & 2-Propanol & 300 & 3 & Estimate: $0.01 * \mathrm{MeOH}$ \\
\hline & 1-Butanol & 40 & 3 & Ratio to Butanal \\
\hline & 2-Butanol & 40 & 3 & Ratio to Butanal \\
\hline & 2-Methyl-1-Propanol & 40 & 3 & Ratio to Butanal \\
\hline & 2-Methyl-2-Propanol & 40 & 3 & Ratio to Butanal \\
\hline & 3-Pentanol & 40 & 3 & Same as 1-Butanol \\
\hline Ethers & MTBE & 1000 & 2 & A/C (MTBE/Btnl)*Btnl (@T0 est) \\
\hline Alkyl Nitrates & Methylnitrate & 5 & 1 & $0.5 \mathrm{~A} / \mathrm{C}$ close in average \\
\hline \multirow[t]{27}{*}{ (ANs) } & Ethylnitrate & 3 & 1 & $0.5 \mathrm{~A} / \mathrm{C}$ close in average \\
\hline & n-Propylnitrate & 2 & 1 & $0.5 \mathrm{~A} / \mathrm{C}$ close in average \\
\hline & i-Propylnitrate & 20 & 1 & $0.5 \mathrm{~A} / \mathrm{C}$ close in average \\
\hline & 2-Butylnitrate & 20 & 1 & $0.5 \mathrm{~A} / \mathrm{C}$ close in average \\
\hline & 2-Methyl-2-Propylnitrate & 10 & 3 & Comparison w/other ANs \\
\hline & 2-Methyl-Propylnitrate & 10 & 3 & Comparison w/other ANs \\
\hline & n-Butylnitrate & 3 & 3 & Comparison w/other ANs \\
\hline & 1-Pentylnitrate & 10 & 3 & Comparison w/other ANs \\
\hline & 2-Methyl-2-Butylnitrate & 10 & 3 & Comparison w/other ANs \\
\hline & 2-Methyl-3-Butylnitrate & 10 & 3 & Comparison w/other ANs \\
\hline & 2-Methyl-Butylnitrate & 10 & 3 & Comparison w/other ANs \\
\hline & 2-Pentylnitrate & 10 & 3 & $0.5 \mathrm{~A} / \mathrm{C}$ close in average \\
\hline & 3-Pentylnitrate & 5 & 1 & Comparison w/other ANs \\
\hline & neo-Pentylnitrate & 1 & 3 & Comparison w/other ANs \\
\hline & 1-Hexylnitrate & 10 & 3 & Comparison w/other ANs \\
\hline & 2,2-dimethyl-Butylnitrate & 10 & 3 & Comparison w/other ANs \\
\hline & 2,3-dimethyl-Butylnitrate & 10 & 3 & Comparison w/other ANs \\
\hline & 2-Hexylnitrate & 10 & 3 & Comparison w/other ANs \\
\hline & 2-methyl-1-Pentylnitrate & 3 & 3 & Comparison w/other ANs \\
\hline & 2-methyl-2-Pentylnitrate & 10 & 3 & Comparison w/other ANs \\
\hline & 2-methyl-3-Pentylnitrate & 10 & 3 & Comparison w/other ANs \\
\hline & 2-methyl-4-Pentylnitrate & 10 & 3 & Comparison w/other ANs \\
\hline & 3,3-dimethyl-Butylnitrate & 10 & 3 & Comparison w/other ANs \\
\hline & 3-Hexylnitrate & 10 & 3 & Comparison w/other ANs \\
\hline & 3-methyl-1-Pentylnitrate & 3 & 3 & Comparison w/other ANs \\
\hline & 3-methyl-2-Pentylnitrate & 10 & 3 & Comparison w/other ANs \\
\hline & 3-methyl-3-Pentylnitrate & 10 & 3 & Comparison w/other ANs \\
\hline \multirow[t]{4}{*}{ Meteorology } & Temperature, $\mathrm{C}$ & 19 & & A/C outflow average \\
\hline & Pressure, mb & 727 & & A/C outflow average \\
\hline & Relative Humidity, \% & 21.9 & & A/C outflow average \\
\hline & Ozone column, DU & 244 & & A/C outflow average \\
\hline
\end{tabular}

a Twenty-four hour median of measured values at $T_{0}$ site by Blake et al., UC-Irvine.

$\mathrm{b}$ Twenty-four hour median of measured values at $T_{0}$ site reported by Kolb et al. in the database. Some measurements are from the mobile Aerodyne sampling van while others are from non-Aerodyne investigators.

c Average of C-130 and DC-8 aircraft (A/C) observations in outflow plume.

d Average of C-130 and DC-8 aircraft (A/C) observations within MCMA basin.

e Twenty-four hour average as estimated from other data by Apel et al. (2010).

${ }^{\mathrm{f}}$ Estimated from fit of measured values of same class of compounds versus carbon number. 
in modeled $\mathrm{CH}_{2} \mathrm{O}$ then represents the $1 \sigma$ uncertainty in calculated $\mathrm{CH}_{2} \mathrm{O}$ for that given constraint. The individual uncertainties for each constraint were combined in quadrature for a total model constraint uncertainty. While the given uncertainties in measurements of the model constraints include both random and systematic errors, we consider the propagated uncertainty to be largely random in nature, and henceforth all mention of model uncertainty refers to such model constraint uncertainty, unless stated otherwise. For conditions over the remote Pacific, the model constraint uncertainty for $\mathrm{CH}_{2} \mathrm{O}$ (converted to $2 \sigma$ ) ranges from 22$34 \%$ throughout the altitude regime considered. Values over the continental US and Mexico range from 8-35\%. These ranges are meant to show the model constraint uncertainty range, however, individual uncertainties for each model point were used in the calculation of the combined measurement and model uncertainty. These ranges span the $24 \%(2 \sigma)$ random model component value of Frost et al. (2002). Differences with Frost et al. (2002) reflect: (1) the model input uncertainties for each important measurement are better characterized here; (2) the instruments have improved performance since the 1997 Frost study; (3) the spatial coverage and time of year are different between the two studies; and most importantly (4) individual point-by-point model uncertainties were calculated and used here rather than a single median value. The combined random measurement and model constraint uncertainty ( $2 \sigma$ level) for each altitude range bin was then estimated by quadrature addition of the measurement LOD with the model constraint uncertainty, and the average value for each altitude bin was determined. In the boundary layer, the combined uncertainty for the ratios are calculated for every comparison point on the hydrocarbon time base and the median value is \pm 0.13 .

In addition, the model kinetic uncertainty was calculated using a Monte Carlo approach. Median environmental and chemical conditions were found for various altitude levels for the US/Mexico portion and for the Pacific portion of INTEXB. For each set of input conditions, the model kinetic uncertainty was calculated by running 2500 simulations whereby each of 105 model kinetic reaction rates and 16 photolytic rates was randomly and independently varied within its referenced $1 \sigma$ uncertainty. The standard deviations of the resulting range of predictions can be used to define the model $\mathrm{ki}$ netic uncertainty for various predicted radical species. While this component of model uncertainty is generally considered systematic, it can vary, depending upon changes in the chemical and environmental regimes. This component of uncertainty $(2 \sigma)$ was calculated to range from $50 \%-62 \%$ (boundary layer - high altitudes, Pacific) and 34\%-68\% (boundary layer - high altitudes, Houston) for $\mathrm{CH}_{2} \mathrm{O}$ during INTEX-B.

\section{Appendix B}

\section{Overview of past TDLAS comparisons with other techniques}

Comparisons of an earlier version of the present airborne system employing a different $\mathrm{CH}_{2} \mathrm{O}$ absorption feature produced results that agreed with long-path ultraviolet/visible DOAS results to within $5 \%$ when both instruments sampled the same air mass unperturbed by local anthropogenic and meteorological influences (Harder et al., 1997). An earlier version of the present airborne TDLAS system (employing the same $2831.6 \mathrm{~cm}^{-1}$ absorption line) was also compared with three continuous non-spectroscopic methods, including a coil Hantzsch system, during an extensive groundbased $\mathrm{CH}_{2} \mathrm{O}$ intercomparison study discussed by Gilpin et al. (1997). After correcting for calibration differences using a common standard provided by the TDLAS system, all four instruments retrieved equivalent ambient $\mathrm{CH}_{2} \mathrm{O}$ mixing ratios within $\pm 18 \%$, and two of the non-spectroscopic instruments were within $4 \%$ of the TDLAS retrievals. An earlier version of the present TDLAS system was also compared with one of the non-spectroscopic methods in the Gilpin et al. study onboard a NOAA aircraft during the 1997 NARE study (Fried et al., 2002). A bivariant least squares fit of this instrument versus the TDLAS for 665 overlapping 5min time coincident intervals resulted in a slope of 0.987 and intercept of $0.027 \mathrm{ppbv}$ for mixing ratios up to $2 \mathrm{ppbv}$. Furthermore, the two instruments measured identical $\mathrm{CH}_{2} \mathrm{O}$ mixing ratios to within $\sim 0.1 \mathrm{ppbv}$, and more typically within $0.08 \mathrm{ppbv}$, in 3 altitude bins up to $\sim 8 \mathrm{~km}$ over the $0-0.8 \mathrm{ppbv}$ range. Finally, Wert et al. (2003) compared airborne $\mathrm{CH}_{2} \mathrm{O}$ measurements using an earlier version of the present TDLAS system with a ground based DOAS system operated by Stutz during the 2000 Texas Air Quality Study. During aircraft overflights (40-60 $\mathrm{m}$ above the ground) of the DOAS sampling site when three different DOAS paths spanning altitudes from 2 to $50 \mathrm{~m}$ above ground indicated uniform mixing, the agreement between the two techniques was within $5 \%$.

\section{Appendix C}

\section{Overview of present airborne TDL comparisons with ground based measurements}

There were nine different time periods when either the DC-8 or the $\mathrm{C}-130$ passed very close to ground sampling sites over Mexico City and when ground-based $\mathrm{CH}_{2} \mathrm{O}$ measurements were also acquired employing a Hantzsch system operated by Junkermann's research group (see Hak et al., 2005 for a description of this instrument) and/or a DOAS instrument operated by Volkamer's group). Appendix Table A1 tabulates the pertinent information regarding the two overpasses 
by the DC- 8 while Appendix Tables A2a and A2b tabulate $\mathrm{C}-130$ overpasses. Numerous diagnostics from ground, airborne, and balloon-sounding systems indicated uniform sampled air between the airborne and ground-based measurements. These diagnostics include: airborne aerosol measurements using the NASA Langley lidar system on the DC-8 (Browell et al., 2003) and the NCAR SABL Lidar system on the C-130, a ground-based micro-pulsed lidar system located at $T_{1}, 915 \mathrm{MHz}$ radar wind profilers operated by Phillips and Knupp at the University of Alabama (see Cronce et al., 2007) and a Ceilometer backscatter profiler, and balloon soundings of constant potential temperature.

The C-130 overpasses close to the $T_{0}, T_{1}$, and $T_{2}$ groundsampling sites are listed in Appendix Tables A2a and A2b. Appendix Table A2a lists time periods when ground-based $\mathrm{CH}_{2} \mathrm{O}$ measurements were acquired employing the Hantzsch system operated by Junkermann's research group and Appendix Table A2b lists time periods when the University of Colorado's MAX-DOAS system acquired vertical column measurements of $\mathrm{CH}_{2} \mathrm{O}$. When used with boundary layer height estimates from Lidar and/or wind profiler measurements and the assumption of vertical uniformity, the MAXDOAS column measurements can be used to derive $\mathrm{CH}_{2} \mathrm{O}$ mixing ratios for comparisons with the $\mathrm{C}-130$ measurements. Since boundary layer height estimates may be uncertain in some cases, vertical column derived $\mathrm{CH}_{2} \mathrm{O}$ mixing ratios were corrected by the ratio of DOAS derived $\mathrm{NO}_{2}$-to C-130 in situ measurements of $\mathrm{NO}_{2}$ by Weinheimer's group. These corrections assume that the lifetimes of both gases are longer than vertical mixing times and both gases have similar vertical distributions, i.e. that mixing (or lack thereof) does not introduce new sources of one gas relative to the other. During times of the DC- 8 overpasses mixing is well developed, and gradients are expected to be small. DOAS derived $\mathrm{NO}_{2}$-to C-130 measurement ratios were within $11 \%$ of the same ratios for $\mathrm{CH}_{2} \mathrm{O}$, suggesting the above assumptions should be valid. Although the C-130 and DOAS measurements times indicated in Table A2b were not precisely time coincident, the time differences were within $\sim 0.5$ to $1.5 \mathrm{~h}$.

Acknowledgements. The National Center for Atmospheric Research is operated by the University Corporation for Atmospheric Research under the sponsorship of the National Science Foundation. This research was supported by funds from the National Aeronautics and Space Administration's Global Tropospheric Program and by funds from NSF in support of the MIRAGE Study. The authors acknowledge the NASA/University of North Dakota DC-8 staff and crew for their support and assistance and Jack Fox and Ken Harris, both formerly with NCAR. We also acknowledge Bruce Morley and Gordon Farquharson for the SABL (Scanning Aerosol Backscatter Lidar) aerosol measurements on the C-130 and Dustin Phillips and Kevin Knupp at the University of Alabama in Huntsville for their profiler data. We also acknowledge Thomas Wagner, Ulrich Platt and Luisa Molina for loan of equipment and support in generating the DOAS dataset.
Edited by: L. Molina

\section{References}

Atkinson, R., Baulch, D. L., Cox, R. A., Crowley, J. N., Hampson, R. F., Hynes, R. G., Jenkin, M. E., Rossi, M. J., Troe, J., and IUPAC Subcommittee: Evaluated kinetic and photochemical data for atmospheric chemistry: Volume II - gas phase reactions of organic species, Atmos. Chem. Phys., 6, 3625-4055, doi:10.5194/acp-6-3625-2006, 2006.

Apel, E. C., Emmons, L. K., Karl, T., Flocke, F., Hills, A. J., Madronich, S., Lee-Taylor, J., Fried, A., Weibring, P., Walega, J., Richter, D., Tie, X., Mauldin, L., Campos, T., Weinheimer, A., Knapp, D., Sive, B., Kleinman, L., Springston, S., Zaveri, R., Ortega, J., Voss, P., Blake, D., Baker, A., Warneke, C., Welsh-Bon, D., de Gouw, J., Zheng, J., Zhang, R., Rudolph, J., Junkermann, W., and Riemer, D. D.: Chemical evolution of volatile organic compounds in the outflow of the Mexico City Metropolitan area, Atmos. Chem. Phys., 10, 2353-2375, doi:10.5194/acp-10-23532010, 2010.

Bertman, S. B., Roberts, J. M., Parrish, D. D., Buhr, M. P., Goldman, P. D., Kuster, W. C., Fehsenfeld, F. C., Montzka, S. A., and Westberg, H.: Evolution of Alkyl Nitrates with Air-Mass Age, J. Geophys. Res., 100, 22805-22813, 1995.

Bloss, C., Wagner, V., Jenkin, M. E., Volkamer, R., Bloss, W. J., Lee, J. D., Heard, D. E., Wirtz, K., Martin-Reviejo, M., Rea, G., Wenger, J. C., and Pilling, M. J.: Development of a detailed chemical mechanism (MCMv3.1) for the atmospheric oxidation of aromatic hydrocarbons, Atmos. Chem. Phys., 5, 641-664, doi:10.5194/acp-5-641-2005, 2005.

Browell, E. V., Fenn, M. A., Butler, C. F., Grant, W. B., Brackett, V. G., Hair, J. W., Avery, M. A., Newell, R. E., Hu, Y., Fuelberg, H. E., Jacob, D. J., Anderson, B. E., Atlas, E. L., Blake, D. R., Brune, W. H., Dibb, J. E., Fried, A., Heikes, B. G., Sachse, G. W., Sandholm, S. T., Singh, H. B., Talbot, R. W., Vay, S. A., Weber, R. J., and Bartlett, K. B.: Large-Scale Ozone and Aerosol Distributions, Air Mass Characteristics, and Ozone Fluxes Over the Western Pacific Ocean in Late Winter/Early Spring, J. Geophys. Res., 108, 8805, doi:10.1029/2002JD003290, 2003.

Carlier, P., Hannachi, H., and Mouvier, G.: The chemistry of carbonyl compounds in the atmosphere: A review, Atmos. Environ., 20, 2079-2099, 1986.

Coburn, S., Dix, B., Sinreich, R., and Volkamer, R.: The CU ground MAX-DOAS instrument: characterization of RMS noise limitations and first measurements near Pensacola, FL of BrO, IO, and CHOCHO, Atmos. Meas. Tech., 4, 2421-2439, doi:10.5194/amt-4-2421-2011, 2011.

Crawford, J. H., Davis, D., Olson, J., Chen, G., Liu, S., Gregory, G., Barrick, J., Sachse, G., Sandholm, S., Heikes, B., Singh, H., and Blake, D.: Assessment of upper tropospheric $\mathrm{HO}_{\mathrm{x}}$ sources over the tropical Pacific based on NASA GTE/PEM data: net effect on $\mathrm{HO}_{\mathrm{x}}$ and other photochemical parameters, J. Geophys. Res., 104, 16255-16273, 1999.

Cronce, M., Rauber, R. M., Knupp, K. R., Jewett, B. F., Walters, J. T., and Phillips, D.: Vertical Motions in Precipitation Bands in Three Winter Cyclones, J. Am. Meteorol. Soc., 46, 1523-1543, doi:10.1175/JAM2533.1, 2007. 
Crounse, J. D., Paulot, F., Kjaergaard, H. G., and Wennberg, P. O.: Peroxy radical isomerization in the oxidation of isoprene, Phys. Chem. Chem. Phys., 13, 13607-13613, 2011.

Dasgupta, P. K., Li, J., Zhang, G., Luke, W. T., McClenny, W. A., Stutz, J., and Fried, A.: Summertime ambient formaldehyde in five U.S. metropolitan areas: Nashville, Atlanta, Houston, Philadelphia, and Tampa, Environ. Sci. Technol., 39, 4767-4783, 2005.

Dusanter, S., Vimal, D., Stevens, P. S., Volkamer, R., Molina, L. T., Baker, A., Meinardi, S., Blake, D., Sheehy, P., Merten, A., Zhang, R., Zheng, J., Fortner, E. C., Junkermann, W., Dubey, M., Rahn, T., Eichinger, B., Lewandowski, P., Prueger, J., and Holder, $\mathrm{H}$.: Measurements of $\mathrm{OH}$ and $\mathrm{HO}_{2}$ concentrations during the MCMA-2006 field campaign - Part 2: Model comparison and radical budget, Atmos. Chem. Phys., 9, 6655-6675, doi:10.5194/acp-9-6655-2009, 2009.

Fried, A., Lee, Y.-N., Frost, G., Wert, B., Henry, B., Drummond, J. R., Hubler, G., and Jobson, T.: Airborne $\mathrm{CH}_{2} \mathrm{O}$ measurements over the North Atlantic during the 1997 NARE campaign: instrument comparisons and distributions, J. Geophys. Res., 107, 4039, doi:10.1029/2000JD000260, 2002.

Fried, A., Wang, Y., Cantrell, C., Wert, B., Walega, J., Ridley, B., Atlas, E., Shetter, R., Lefer, B., Coffey, M.T., Hannigan, J., Blake, D., Blake, N., Meinardi, S., Talbot, B., Dibb, J., Scheuer, E., Wingenter, O., Snow, J., Heikes, B., and Ehhalt, D.: Tunable Diode Laser Measurements of Formaldehyde During the TOPSE 2000 Study: Distributions, Trends, and Model Comparisons, J. Geophys. Res., 108, 8365, doi:10.1029/2002JD002208, 2003a.

Fried, A., Crawford, J., Olson, J., Walega, J., Potter, W., Wert, B., Jordan, C., Anderson, B., Shetter, R., Lefer, B., Blake, D., Blake, N., Meinardi, S., Heikes, B., O’Sullivan, D., Snow, J., Fuelberg, H., Kiley, C. M., Sandholm, S., Tan, D., Sachse, G., Singh, H., Faloona, I., Harward, C. N., and Carmichael, G. R.: Airborne Tunable Diode Laser Measurements of Formaldehyde During TRACE-P: Distributions and Box-Model Comparisons, J. Geophys. Res., 108, 8798, doi:10.1029/2003JD003451, 2003b.

Fried, A., Walega, J. G., Olson, J. R., Crawford, J. H., Chen, G., Weibring, P., Richter, D., Roller, C., Tittel, F. K., Heikes, B. G., Snow, J. A., Shen, H., O'Sullivan, D. W., Porter, M., Fuelberg, H., Halland, J., and Millet, D.: Formaldehyde Over North America and the North Atlantic During the Summer 2004 INTEX Campaign: Methods, Observed Distributions, and Measurement-Model Comparisons, J. Geophys. Res., 113, D10302, doi:10.1029/2007JD009185, 2008a.

Fried, A., Olson, J. R., Walega, J. G., Crawford, J. H., Chen, G., Weibring, P., Richter, D., Roller, C., Tittel, F., Porter, M., Fuelberg, H., Halland, J., Bertram, T. H., Cohen, R. C., Pickering, K., Heikes, B. G., Snow, J. A., Shen, H., O'Sullivan, D. W., Brune, W. H., Ren, X., Blake, D. R., Blake, N., Sachse, G., Diskin, G. S., Podolske, J., Vay, S. A., Shetter, R. E., Hall, S. R., Anderson, B. E., Thornhill, L., Clark, A. D., McNaughton, C. S., Singh, H. B., Avery, M. A., Huey, G., Kim, S., and Millet, D. B.: Role of Convection in Redistributing Formaldehyde to the Upper Troposphere Over North America and the North Atlantic During the Summer 2004 INTEX Campaign, J. Geophys. Res., 113, D17306, doi:10.1029/2007JD009760, 2008b.

Frost, G. J., Fried, A., Lee, Y.-N., Wert, B., Henry, B., Drummond, J. R., Evans, M. J., Fehsenfeld, F. C., Goldan, P. D., Holloway, J. S., Hubler, G., Jakoubek, R., Jobson, B. T., Knapp, K., Kuster,
W. C., Roberts, J., Rudolph, J., Ryerson, T. B., Stohl, A., Stroud, C., Sueper, D. T., Trainer, M., and Williams, J.: Comparisons of Box Model Calculations and Measurements of Formaldehyde from the 1997 North Atlantic Regional Experiment, J. Geophys. Res., 107, 4060, doi:10.1029/2001JD000896, 2002.

Garcia, A. R., Volkamer, R., Molina, L. T., Molina, M. J., Samuelson, J., Mellqvist, J., Galle, B., Herndon, S. C., and Kolb, C. E.: Separation of emitted and photochemical formaldehyde in Mexico City using a statistical analysis and a new pair of gas-phase tracers, Atmos. Chem. Phys., 6, 4545-4557, doi:10.5194/acp-64545-2006, 2006.

Gilpin, T., Apel, E., Fried, A., Wert, B., Calvert, J., Genfa, Z., Dasgupta, P., Harder, J.W., Heikes, B., Hopkins, B., Westberg, H., Kleindienst, T., Lee, Y.-N., Zhou, X., Lonneman, W., and Sewell, S.: Intercomparison of Six Ambient $\left[\mathrm{CH}_{2} \mathrm{O}\right]$ Measurement Techniques, J. Geophys. Res., 102, 21161-21188, 1997.

Hak, C., Pundt, I., Trick, S., Kern, C., Platt, U., Dommen, J., Ordóñez, C., Prévôt, A. S. H., Junkermann, W., Astorga-Lloréns, C., Larsen, B. R., Mellqvist, J., Strandberg, A., Yu, Y., Galle, B., Kleffmann, J., Lörzer, J. C., Braathen, G. O., and Volkamer, R.: Intercomparison of four different in-situ techniques for ambient formaldehyde measurements in urban air, Atmos. Chem. Phys., 5, 2881-2900, doi:10.5194/acp-5-2881-2005, 2005.

Herndon, S. C., Jayne, J. T., Zahniser, M. S., Worsnop, D. R., Knighton, B., Alwine, E., Lamb, B. K., Zavala, M., Nelson, D. D., McManus, J. B., Shorter, J. H., Canagaratna, M. R., Onasch, T. B., and Kolb, C. E.: Characterization of Urban Pollutant Emission Fluxes and Ambient Concentration Distributions using a Mobile Laboratory with Rapid Response Instrumentation, Faraday Discuss., 130, 327-339, 2005.

Harder, J. W., Fried, A., Sewell, S., and Henry, B.: Comparison of tunable diode laser and long-path ultraviolet/visible spectroscopic measurements of ambient formaldehyde concentrations during the $1993 \mathrm{OH}$ Photochemistry Experiment, J. Geophys. Res., 102, 6267-6282, 1997.

Jenkin, M. E., Saunders, S. M., and Pilling, M. J.: The Tropospheric Degradation of Volatile Organic Compounds: A Protocol for Mechanism Development, Atmos. Environ., 31, 81-104, 1997.

Jenkin, M. E., Saunders, S. M., Wagner, V., and Pilling, M. J.: Protocol for the development of the Master Chemical Mechanism, MCM v3 (Part B): tropospheric degradation of aromatic volatile organic compounds, Atmos. Chem. Phys., 3, 181-193, doi:10.5194/acp-3-181-2003, 2003.

Junkermann, W.: On the distribution of formaldehyde in the western Po-Valley, Italy, during FORMAT 2002/2003, Atmos. Chem. Phys., 9, 9187-9196, doi:10.5194/acp-9-9187-2009, 2009.

Kleb, M. M., Chen, G., Crawford, J. H., Flocke, F. M., and Brown, C. C.: An overview of measurement comparisons from the INTEX-B/MILAGRO airborne field campaign, Atmos. Meas. Tech., 4, 9-27, doi:10.5194/amt-4-9-2011, 2011.

Kleinman, L. I., Springston, S. R., Daum, P. H., Lee, Y.-N., Nunnermacker, L. J., Senum, G. I., Wang, J., Weinstein-Lloyd, J., Alexander, M. L., Hubbe, J., Ortega, J., Canagaratna, M. R., and Jayne, J.: The time evolution of aerosol composition over the Mexico City plateau, Atmos. Chem. Phys., 8, 1559-1575, doi:10.5194/acp-8-1559-2008, 2008.

Kormann, R., Fischer, H., de Reus, M., Lawrence, M., Brühl, Ch., von Kuhlmann, R., Holzinger, R., Williams, J., Lelieveld, 
J., Warneke, C., de Gouw, J., Heland, J., Ziereis, H., and Schlager, H.: Formaldehyde over the eastern Mediterranean during MINOS: Comparison of airborne in-situ measurements with 3D-model results, Atmos. Chem. Phys., 3, 851-861, doi:10.5194/acp-3-851-2003, 2003.

Lee, M., Heikes, B. G., Jacob, D. J., Sachse, G., and Anderson, B.: Hydrogen peroxide, organic hydroperoxide, and formaldehyde as primary pollutants from biomass burning, J. Geophys. Res., 102, 1301-1309, 1997.

Lei, W., Zavala, M., de Foy, B., Volkamer, R., and Molina, L. T.: Characterizing ozone production and response under different meteorological conditions in Mexico City, Atmos. Chem. Phys., 8, 7571-7581, doi:10.5194/acp-8-7571-2008, 2008.

Lei, W., Zavala, M., de Foy, B., Volkamer, R., Molina, M. J., and Molina, L. T.: Impact of Primary Formaldehyde on Air Pollution in the Mexico City Metropolitan Area, 9, 2607-2618, 2009.

Lelieveld, J., Butler, T. M., Crowley, J. N., Dillon, T. J., Fischer, H., Ganzeveld, L., Harder, H., Lawrence, M. G., Martinez, M., Taraborrelli, D., and Williams, J.: Atmospheric oxidation capacity sustained by a tropical forest, Nature, 452, 737-740, 2008.

Lurmann, F. W., Lloyd, A. C., and Atkinson, R.: A Chemical Mechanism for Use in Long-Range Transport/Acid Deposition Computer Modeling, J. Geophys. Res., 91, 10905-10936, 1986.

Mao, J., Ren, X., Brune, W. H., Olson, J. R., Crawford, J. H., Fried, A., Huey, L. G., Cohen, R. C., Heikes, B., Singh, H. B., Blake, D. R., Sachse, G. W., Diskin, G. S., Hall, S. R., and Shetter, R. E.: Airborne measurement of $\mathrm{OH}$ reactivity during INTEX-B, Atmos. Chem. Phys., 9, 163-173, doi:10.5194/acp-9-163-2009, 2009.

Martin, B. D., Fuelberg, H. E., Blake, N. J., Crawford, J. H., Logan, J. A., Blake, D. R., and Sachse, G. W.: Long range transport of Asian outflow to the equatorial Pacific, J. Geophys., Res., 108, 8322, doi:10.1029/2001JD001418, 2003.

Molina, L. T., Madronich, S., Gaffney, J. S., Apel, E., de Foy, B., Fast, J., Ferrare, R., Herndon, S., Jimenez, J. L., Lamb, B., Osornio-Vargas, A. R., Russell, P., Schauer, J. J., Stevens, P. S., Volkamer, R., and Zavala, M.: An overview of the MILAGRO 2006 Campaign: Mexico City emissions and their transport and transformation, Atmos. Chem. Phys., 10, 8697-8760, doi:10.5194/acp-10-8697-2010, 2010.

Olaguer, E. P., Rappenglück, B., Lefer, B., Stutz, J., Dibb, J., Griffin, R., Brune, W. H., Shauck, M., Buhr, M., Jeffries, H., Vizuete, W., and Pinto, J. P.: Deciphering the Role of Radical Precursors During the Second Texas Air Quality Study, J. Air Waste Manage. Assoc., 59, 1258-1277, 2009.

Olson, J. R., Crawford, J. H., Davis, D. D., Chen, G., Avery, M. A., Barrick, J. D. W., Sachse, G. W., Vay, S. A., Sandholm, S. T., Tan, D., Brune, W. H., Faloona, I. C., Heikes, B. G., Shetter, R. E., Lefer, B. L., Singh, H. B., Talbot, R. W., and Blake, D. R.: Seasonal differences in the photochemistry of the South Pacific: A comparison of observations and model results from PEM-Tropics A and B, J. Geophys. Res., 106, 32749-32766, 2001.

Olson, J. R., Crawford, J. H., Chen, G., Brune, W. H., Faloona, I. C., Tan, D., Harder, H., and Martinez, M.: A Reevaluation of $\mathrm{HO}_{\mathrm{x}}$ Observations from NASA Field Campaigns, J. Geophys. Res., 111, D10301, doi:10.1029/2005JD006617, 2006.

Peeters, J., Nguyen, T. L., and Vereecken, L.: $\mathrm{HO}_{\mathrm{x}}$ radical regeneration in the oxidation of isoprene, Phys. Chem. Chem. Phys., 11,
5935-5939, 2009.

Perring, A. E., Bertram, T. H., Farmer, D. K., Wooldridge, P. J., Dibb, J., Blake, N. J., Blake, D. R., Singh, H. B., Fuelberg, H., Diskin, G., Sachse, G., and Cohen, R. C.: The production and persistence of SRONO2 in the Mexico City plume, Atmos. Chem. Phys., 10, 7215-7229, doi:10.5194/acp-10-7215-2010, 2010.

Rappenglück, B., Dasgupta, P. K., Leuchner, M., Li, Q., and Luke, W.: Formaldehyde and its relation to $\mathrm{CO}, \mathrm{PAN}$, and $\mathrm{SO}_{2}$ in the Houston-Galveston airshed, Atmos. Chem. Phys., 10, 2413 2424, doi:10.5194/acp-10-2413-2010, 2010.

Ren., X., Olson, J. R., Crawford, J. H., Brune, W. H., Mao, J., Long, R. B., Chen, Z., Chen, G., Avery, M. A., Sachse, G. W., Barrick, J. D., Diskin, G. S., Huey, L. G., Fried, A., Cohen, R. C., Heikes, B., Wennberg, P. O., Singh, H. B., Blake, D. R., and Shetter, R. E.: $\mathrm{HO}_{\mathrm{x}}$ Chemistry During INTEX-A 2004: Observation, Model Calculation, and Comparison with Previous Studies, J. Geophys. Res., 113, D05310, doi:10.1029/2007JD009166, 2008.

Roehl, C. A., Nizkorodov, S. A., Blake, G. A., and Wennberg, P. O.: Photodissociation of Peroxynitric acid in the Near IR, J. Phys. Chem. A, 106, 3766-3772, 2002.

Roller, C., Fried, A., Walega, J., Weibring, P., and Tittel, F.: Advances in Hardware, System Diagnostics Software, and Acquisition Procedures for High Performance Airborne Tunable Diode Laser Measurements of Formaldehyde, Appl. Phys. B, 82, 247264, 2006.

Sander, S. P., Friedl, R. R., Golden, D. M., Kurylo, M. J., Moortgat, G. K., Keller-Rudek, H., Wine, P. H., Ravishankara, A. R., Kolb, C. E., Molina, M. J., Finlayson-Pitts, B. J., Huie, R. E., and Orkin, V. L.: Chemical Kinetics and Photochemical Data for Use in Atmospheric Studies Evaluation Number 15, JPL Publication 06-2, 2006.

Saunders, S. M., Jenkin, M. E., Derwent, R. G., and Pilling, M. J.: Protocol for the development of the Master Chemical Mechanism, MCM v3 (Part A): tropospheric degradation of nonaromatic volatile organic compounds, Atmos. Chem. Phys., 3, 161-180, doi:10.5194/acp-3-161-2003, 2003.

Singh, H. B., Brune, W. H., Crawford, J. H., Flocke, F., and Jacob, D. J.: Chemistry and transport of pollution over the Gulf of Mexico and the Pacific: spring 2006 INTEX-B campaign overview and first results, Atmos. Chem. Phys., 9, 2301-2318, doi:10.5194/acp-9-2301-2009, 2009.

Sinreich, R., Coburn, S., Dix, B., and Volkamer, R.: Ship-based detection of glyoxal over the remote tropical Pacific Ocean, Atmos. Chem. Phys., 10, 11359-11371, doi:10.5194/acp-1011359-2010, 2010.

Stickler, A., Fischer, H., Williams, J., de Reus, M., Sander, R., Lawrence, M. G., Crowley, J. N., and Lelieveld, J.: Influence of Summertime Deep Convection on Formaldehyde in the Middle and Upper Troposphere Over Europe, J. Geophys. Res., 111, D14308, doi:10.1029/2005JD007001, 2006.

Stone, D., Evans, M. J., Edwards, P. M., Commane, R., Ingham, T., Rickard, A. R., Brookes, D. M., Hopkins, J., Leigh, R. J., Lewis, A. C., Monks, P. S., Oram, D., Reeves, C. E., Stewart, D., and Heard, D. E.: Isoprene oxidation mechanisms: measurements and modelling of $\mathrm{OH}$ and $\mathrm{HO}_{2}$ over a South-East Asian tropical rainforest during the OP3 field campaign, Atmos. Chem. Phys., 11, 6749-6771, doi:10.5194/acp-11-6749-2011, 2011. 
Volkamer, R., Sheehy, P., Molina, L. T., and Molina, M. J.: Oxidative capacity of the Mexico City atmosphere - Part 1: A radical source perspective, Atmos. Chem. Phys., 10, 6969-6991, doi:10.5194/acp-10-6969-2010, 2010.
Wert, B. P., Trainer, M., Fried, A., Ryerson, T. B., Henry, B., Potter, W., Angevine, W. M., Atlas, E., Donnelly, S. G., Fehsenfeld, F. C., Frost, G. J., Goldan, P. D., Hansel, A., Holloway, J. S., Hubler, G., Kuster, W. C., Nicks Jr., D. K., Neuman, J. A., Parrish, D. D., Schauffler, S., Stutz, J., Sueper, D. T., Wiedinmyer, C., and Wisthaler, A.: Signatures of terminal alkene oxidation in airborne formaldehyde measurements during TexAQS 2000, J. Geophys. Res., 108, 4104, doi:10.1029/2002JD002502, 2003. 